\title{
Review Article \\ Recent Developments in Homogeneous Advanced Oxidation Processes for Water and Wastewater Treatment
}

\author{
M. Muruganandham, ${ }^{1,2}$ R. P. S. Suri, ${ }^{1}$ Sh. Jafari, ${ }^{2}$ M. Sillanpää, ${ }^{2}$ Gang-Juan Lee, ${ }^{3}$ \\ J. J. $\mathrm{Wu}^{3}$ and $\mathrm{M}$. Swaminathan ${ }^{4}$ \\ ${ }^{1}$ Department of Civil and Environmental Engineering, Water \& Environmental Technology (WET) Center, \\ Temple University, Philadelphia, PA 19122, USA \\ ${ }^{2}$ Laboratory of Green Chemistry, Faculty of Technology, Lappeenranta University of Technology, \\ Patteristonkatu 1, 50100 Mikkeli, Finland \\ ${ }^{3}$ Department of Environmental Engineering and Science, Feng Chia University, No. 100 Wenhwa Road, \\ Seatwen District 407, Taichung, Taiwan \\ ${ }^{4}$ Department of Chemistry, Annamalai University, Annamalai Nagar 608002, India
}

Correspondence should be addressed to M. Muruganandham; mmuruganandham@temple.edu and J. J. Wu; jjwu@fcu.edu.tw

Received 31 May 2013; Accepted 21 October 2013; Published 26 February 2014

Academic Editor: Vincenzo Augugliaro

Copyright (c) 2014 M. Muruganandham et al. This is an open access article distributed under the Creative Commons Attribution License, which permits unrestricted use, distribution, and reproduction in any medium, provided the original work is properly cited.

This paper reports on recent developments in homogeneous Advanced Oxidation Processes (AOPs) for the treatment of water and wastewater. It has already been established that AOPs are very efficient compared to conventional treatment methods for degradation and mineralization of recalcitrant pollutants present in water and wastewater. AOPs generate a powerful oxidizing agent, hydroxyl radical, which can react with most of the pollutants present in wastewater. Therefore, it is important to discuss recent developments in AOPs. The homogeneous AOPs such as $\mathrm{O}_{3}, \mathrm{UV} / \mathrm{O}_{3}, \mathrm{UV} / \mathrm{O}_{3} / \mathrm{H}_{2} \mathrm{O}_{2}$, and $\mathrm{UV} / \mathrm{H}_{2} \mathrm{O}_{2}, \mathrm{Fe}^{2+} / \mathrm{H}_{2} \mathrm{O}_{2}, \mathrm{UV} / \mathrm{Fe}^{2+} / \mathrm{H}_{2} \mathrm{O}_{2}$ on the degradation of pollutants are discussed in this paper. The influence on the process efficiency of various experimental parameters such as solution $\mathrm{pH}$, temperature, oxidant concentration, and the dosage of the light source is discussed. A list of contaminants used for degradation by various AOPs and the experimental conditions used for the treatment are discussed in detail.

\section{Introduction}

Wastewater is water that contains various pollutants, which means it cannot be used like pure water and should not be disposed of in a manner dangerous to humans, living organisms, and the environment. Water pollution has a serious impact on all living creatures, adversely affecting water use for drinking, household needs, recreation, fishing, transportation, and commerce. It has been estimated that the total global volume of wastewater produced in 1995 was in excess of $1,500 \mathrm{~km}^{3}$ [1]. On July 28, 2010, the United Nations General Assembly declared safe and clean drinking water and sanitation a human right essential to the full enjoyment of life and all other human rights [2]. It is a concern that nearly 900 million people in the world do not have access to safe drinking water. Approximately 1.5 million children under five die every year as a result of diseases linked to a lack of access to water and sanitation as indicated by World Health Organization (WHO) [3]. It was estimated that about 1.8 million deaths annually are due to lack of access to safe drinking water and poor sanitation.

In the past, economically viable chlorination has been used for water treatment. Yet the potentially adverse health effects of the by-products formed, together with raised drinking water standards, have led researchers to search for effective and economical alternatives to chlorinating drinking water $[4,5]$. Various wastewater treatment processes have been tried using physical, chemical, and biological methods [6-12]. Some of these methods have disadvantages, however, and cannot be applied for large scale treatment. 
TABLE 1: The oxidation potential of various reactive species.

\begin{tabular}{lc}
\hline Substance & Potential $(\mathrm{V})$ \\
\hline Hydroxyl radical $(\cdot \mathrm{OH})$ & 2.86 \\
Oxygen $(\mathrm{O})$ & 2.42 \\
Ozone molecule $\left(\mathrm{O}_{3}\right)$ & 2.07 \\
Hydrogen peroxide $\left(\mathrm{H}_{2} \mathrm{O}_{2}\right)$ & 1.78 \\
Chlorine $\left(\mathrm{Cl}_{2}\right)$ & 1.36 \\
Chlorine dioxide $\left(\mathrm{ClO}_{2}\right)$ & 1.27 \\
Oxygen molecule $\left(\mathrm{O}_{2}\right)$ & 1.23 \\
\hline
\end{tabular}

For example, one drawback of precipitation methods is sludge formation. Chemical coagulation and flocculation use a large amount of chemicals and the generated sludge may contain hazardous materials, so sludge disposal remains a problem. Adsorption techniques have been used widely for the removal of various water and wastewater pollutants. Their disadvantage is that the pollutants may only transfer to the adsorbent, which needs to be regenerated regularly, resulting in additional costs. Membrane technologies such as ultrafiltration, nanofiltration, and reverse osmosis have been used for the full scale treatment and reuse of water and chemicals. Yet these methods have several operational difficulties in addition to high capital costs. Thus physical methods may not be suitable for the complete removal of pollutants from the environment. Similarly, two different basic biological wastewater treatment methods have been employed: aerobic and anaerobic treatments. These methods also do not completely remove the high concentration of pollutants present in wastewater. Other biological methods involve cost-effectiveness or operational difficulties, making biological means unsuitable for wastewater treatment.

Among the chemical methods, oxidation is efficient and applicable to large scale wastewater treatment. Generally air, oxygen, ozone, and oxidants such as $\mathrm{NaOCl}$ and $\mathrm{H}_{2} \mathrm{O}_{2}$ are used for chemical treatment. The oxidation potential of some of the oxidants is listed in Table 1. The basic chemical oxidation process with air and oxygen also occurs in nature, but it is no longer sufficient for highly polluted wastewater. Therefore there is a significant need to develop a wastewater treatment process which can remove the pollutants effectively by a simple method.

Advanced oxidation processes (AOPs) for wastewater treatment have received a great deal of attention in recent years. AOPs generate the highly reactive hydroxyl radical $\left({ }^{\circ} \mathrm{OH}\right)$ to degrade the recalcitrant chemicals present in wastewater [13-15]. These $\mathrm{OH}$ radicals attack the most organic molecules rapidly and nonselectively. The versatility of AOPs is also enhanced by the fact that they offer various alternative methods of hydroxyl radical production, thus allowing a better compliance with specific treatment requirements. The eco-friendly end product is the special feature of these AOPs, which are more efficient as they are capable of mineralizing a wide range of organic pollutants.
Interestingly, AOPs can make use of solar energy rather than artificial light sources. The latter rely on high electrical power, which is costly and hazardous.

AOPs such as ozonation $\left(\mathrm{O}_{3}\right)$, ozone combined with hydrogen peroxide $\left(\mathrm{O}_{3} / \mathrm{H}_{2} \mathrm{O}_{2}\right)$ and $\mathrm{UV}$ irradiation $\left(\mathrm{O}_{3} / \mathrm{UV}\right)$ or both $\left(\mathrm{O}_{3} / \mathrm{H}_{2} \mathrm{O}_{2} / \mathrm{UV}\right)$, ozone combined with catalysts $\left(\mathrm{O}_{3}\right.$ /catalysts), $\mathrm{UV} / \mathrm{H}_{2} \mathrm{O}_{2}$, Fenton and photo-Fenton processes $\left(\mathrm{Fe}^{2+} / \mathrm{H}_{2} \mathrm{O}_{2}\right.$ and $\left.\mathrm{Fe}^{2+} / \mathrm{H}_{2} \mathrm{O}_{2} / \mathrm{UV}\right)$, and the ultrasonic process and photocatalysis have been successfully used for wastewater treatment [16-23]. This review reports on recent advances in the aforementioned AOPs for water and wastewater treatment. The authors discuss the principle of hydroxyl radical generation from each $\mathrm{AOP}$, the influence of various experimental parameters, and their consequences for the treatment process.

\subsection{Ozone Based Advanced Oxidation Processes}

(i) Ozonation. Ozone is an environmentally friendly oxidant since it decomposes into oxygen without producing selfderived by-products in the oxidation reaction. It is widely used in the purification of drinking water, the treatment of wastewater and process water, the sterilization of water in artificial pools, and so forth. In an ozonation process, two possible oxidizing actions may be considered. The first or direct method involves the reaction between ozone dissolved compounds. The second is known as the radical method because of the reactions between the hydroxyl radicals generated in ozone decomposition and the dissolved compounds [24]. Some oxidation products are refractory to further oxidative conversion by means of ozone, thus preventing a complete abatement of TOC. Yet the high energy cost of direct ozonation limits many practical applications. To increase the efficiency of the ozonation process, the ozone is combined with $\mathrm{H}_{2} \mathrm{O}_{2}$ and UV light, which is expected to increase the removal rate substantially by producing more hydroxyl radicals in the treatment system.

(ii) $\mathrm{O}_{3} / \mathrm{H}_{2} \mathrm{O}_{2}$ Process. Hydroxyl radicals are generated by a radical chain mechanism through the interaction between ozone and $\mathrm{H}_{2} \mathrm{O}_{2}$ as shown in (1). Degradation is facilitated by both ozone and hydroxyl radical:

$$
\mathrm{H}_{2} \mathrm{O}_{2}+2 \mathrm{O}_{3} \longrightarrow 2^{\circ} \mathrm{OH}+3 \mathrm{O}_{2}
$$

(iii) $\mathrm{O}_{3} / U V$ Process. Hydroxyl radicals are generated in the $\mathrm{O}_{3} / \mathrm{UV}$ process by photolysis of ozone in the presence of water as shown in the following:

$$
\mathrm{O}_{3}+h v+\mathrm{H}_{2} \mathrm{O} \longrightarrow 2^{\bullet} \mathrm{OH}+\mathrm{O}_{2}
$$

(iv) $\mathrm{O}_{3} / \mathrm{UV} / \mathrm{H}_{2} \mathrm{O}_{2}$. This combined process may generate hydroxyl radicals in different ways as mentioned in (1)-(2). It is considered to be the most effective treatment process for highly polluted effluents.

Wastewater was treated using the Fenton process or homogeneous AOP employing iron salt with hydrogen 
peroxide. The combination of Fenton's reagent with UV light is called a photo-Fenton reaction. UV light irradiation enhances the efficiency of the Fenton process. The hydroxyl radical generated in the Fenton process is due to the iron catalysed decomposition of $\mathrm{H}_{2} \mathrm{O}_{2}$ as shown in the following:

$$
\mathrm{Fe}^{2+}+\mathrm{H}_{2} \mathrm{O}_{2} \longrightarrow \cdot \mathrm{OH}+\mathrm{Fe}^{3+}+\mathrm{OH}^{-}
$$

In addition to the above reaction the formation of hydroxyl radical also occurs by the following reactions in the photoFenton process shown in the following:

$$
\mathrm{Fe}^{3+}+\mathrm{H}_{2} \mathrm{O}+\mathrm{UV} \longrightarrow \mathrm{OH}+\mathrm{Fe}^{2+}+\mathrm{H}^{+}
$$

This is also attributed to the decomposition of the photoactive $\mathrm{Fe}(\mathrm{OH})^{2+}$ which leads to the addition of the $\mathrm{HO}^{\circ}$ radicals:

$$
\mathrm{Fe}(\mathrm{OH})^{2+}+h v \longrightarrow \mathrm{Fe}^{2+}+{ }^{\circ} \mathrm{OH}
$$

A considerable increase in oxidation power is observed mainly due to the photoreduction of $\mathrm{Fe}$ (III) to $\mathrm{Fe}(\mathrm{II})$, which can react with $\mathrm{H}_{2} \mathrm{O}_{2}$, establishing a cycle:

$$
\mathrm{Fe}^{3+}+\mathrm{H}_{2} \mathrm{O}+h v \longrightarrow \mathrm{Fe}^{2+}+{ }^{\circ} \mathrm{OH}+\mathrm{H}^{+}
$$

Among various AOPs, Fenton's reagent $\left(\mathrm{H}_{2} \mathrm{O}_{2} / \mathrm{Fe}^{2+}\right)$ is one of the most effective methods of organic pollutant oxidation. The advantage of Fenton's reagent is that no energy input is necessary to activate hydrogen peroxide. These processes are economic and can be operated and maintained easily.

1.2. $\mathrm{UV} / \mathrm{H}_{2} \mathrm{O}_{2}$ Process. The $\mathrm{UV} / \mathrm{H}_{2} \mathrm{O}_{2}$ process is a homogeneous advanced oxidation process employing hydrogen peroxide with UV light. Hydrogen peroxide requires activation by an external source such as UV light and the photolysis of hydrogen peroxide generates the effective oxidizing species hydroxyl radical $\left({ }^{\circ} \mathrm{OH}\right)$. The rate of photolysis of $\mathrm{H}_{2} \mathrm{O}_{2}$ depends directly on the incident power or intensity. The hydrogen peroxide decomposition quantum yield is 0.5 at UV (254 nm) irradiation. Solar light could also be used as a radiation source but the rate of photolysis may be low compared to UV light. In this process the dosage needs to be optimized, however, since excess $\mathrm{H}_{2} \mathrm{O}_{2}$ may scavenge hydroxyl radical.

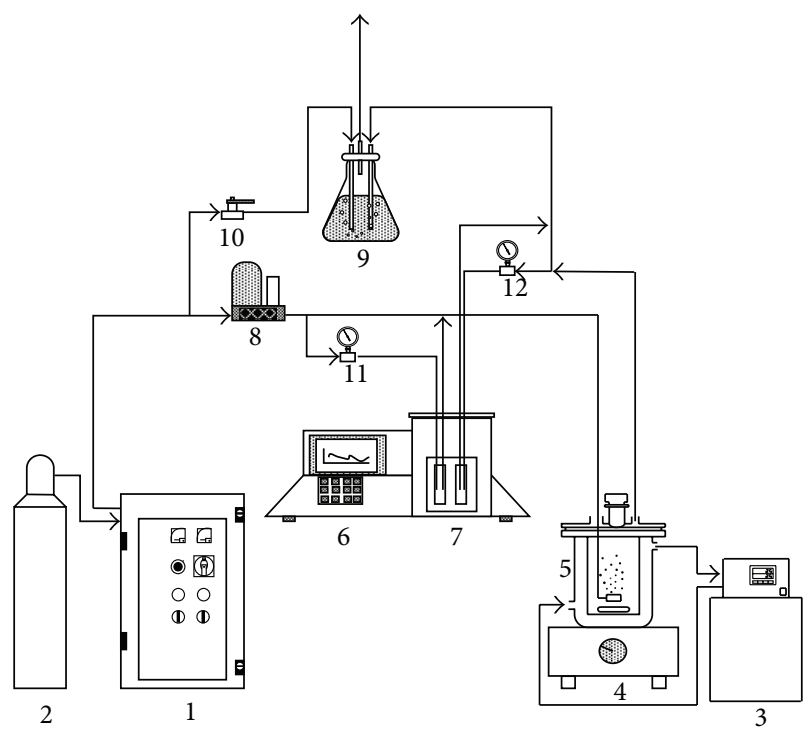

(1) Ozone generator

(2) Oxygen cylinder

(3) Thermostatic water baths

(4) Stirring apparatus

(5) Semibatch reactor

(6) UV spectrophotometer

\subsection{Heterogeneous AOPs}

1.3.1. Catalytic Ozonation Process. Heterogeneous catalytic ozonation is a novel type of AOP that combines ozone with the adsorptive and oxidative properties of solid phase catalysts to decompose pollutants at room temperature. Catalytic ozone decomposition at room temperature is advantageous compared to thermal decomposition in terms of energy conservation since it does not require large volumes of air to be heated. It is therefore a promising advanced oxidation technology for water treatment.

1.3.2. Photocatalysis. Heterogeneous photocatalysis through illumination by UV or visible light on a semiconductor surface generates hydroxyl radicals. The photocatalyst can be used successfully for the effective treatment of pollutants in water and wastewater.

\section{Ozone Based AOPs}

As noted above, ozone reacts with various organic and inorganic compounds in an aqueous solution, either by direct reaction of molecular ozone or through a radical mechanism involving hydroxyl radical induced by the ozone decomposition. Figure 1 shows the experimental setup of the ozonation process. This process is strongly influenced by a number of experimental parameters such as solution $\mathrm{pH}$, influent ozone dosage rate, and temperature. The primary reactions initiated by ozone in water are strongly $\mathrm{pH}$ dependent. Ozone reacts 
TABLE 2: Degradation of some model pollutants by ozone based AOPs under different experimental conditions.

\begin{tabular}{|c|c|c|c|}
\hline Reference & AOPs applied & Pollutant(s) & Conclusions \\
\hline [25] & $\begin{array}{l}\mathrm{O}_{3}, \mathrm{UV} / \mathrm{H}_{2} \mathrm{O}_{2} \\
\mathrm{O}_{3} / \mathrm{H}_{2} \mathrm{O}_{2}, \mathrm{O}_{3} / \mathrm{AC}\end{array}$ & $\begin{array}{l}\text { Diethyl phthalate (DEP) in } \\
\text { ultrapure water, surface water, and } \\
\text { wastewater }\end{array}$ & $\begin{array}{l}\text { The } \mathrm{O}_{3} / \mathrm{AC} \text { process was the most efficient for the } \\
\text { removal of DEP in all three types of water. The } \\
\mathrm{O}_{3} / \mathrm{H}_{2} \mathrm{O}_{2} \text { and } \mathrm{O}_{3} / \mathrm{AC} \text { processes are more efficient } \\
\text { than ozonation alone. }\end{array}$ \\
\hline [26] & $\begin{array}{l}\mathrm{O}_{3}, \mathrm{UV} \text { photolysis, } \\
\mathrm{O}_{3} / \mathrm{UV}, \mathrm{H}_{2} \mathrm{O}_{2} / \mathrm{O}_{3} \\
\mathrm{O}_{3} / \mathrm{H}_{2} \mathrm{O}_{2} / \mathrm{UV}\end{array}$ & 1,4-Dioxane & $\begin{array}{l}\text { The } \mathrm{O}_{3} / \mathrm{H}_{2} \mathrm{O}_{2} / \mathrm{UV} \text { process was most efficient for } \\
\text { 1,4-dioxane removal at } \mathrm{pH} 10 \text {, with } \mathrm{H}_{2} \mathrm{O}_{2}: \mathrm{O}_{3} \text { ratio } \\
\text { of } 0.5 \text {. }\end{array}$ \\
\hline [27] & $\begin{array}{l}\mathrm{O}_{3}, \mathrm{O}_{3} / \mathrm{H}_{2} \mathrm{O}_{2} \\
\mathrm{UV} / \mathrm{H}_{2} \mathrm{O}_{2}, \mathrm{UV} / \mathrm{O}_{3} \\
\mathrm{UV} / \mathrm{H}_{2} \mathrm{O}_{2} / \mathrm{O}_{3}\end{array}$ & Phenol & $\begin{array}{l}\text { The UV/ } \mathrm{H}_{2} \mathrm{O}_{2} / \mathrm{O}_{3} \text { process at } \mathrm{pH} 7 \text { with } \mathrm{H}_{2} \mathrm{O}_{2}= \\
10 \mathrm{mM} \text { was most ecoeffective with } 100 \% \text { of phenol } \\
\text { removal within } 30 \text { min and } 58.0 \% \text { TOC removal } \\
\text { after } 1 \mathrm{~h} \text {. UV/ } \mathrm{H}_{2} \mathrm{O}_{2} / \mathrm{O}_{3} \text { was the most effective } \\
\text { process for phenol wastewater mineralization. }\end{array}$ \\
\hline [28] & $\begin{array}{l}\mathrm{O}_{3}, \mathrm{O}_{3} / \mathrm{H}_{2} \mathrm{O}_{2} \\
\mathrm{UV} / \mathrm{H}_{2} \mathrm{O}_{2}\end{array}$ & $\begin{array}{l}\text { Twenty-four micropollutants } \\
\text { including endocrine disrupting } \\
\text { compounds, pharmaceuticals, and } \\
\text { personal care products }\end{array}$ & $\begin{array}{l}\text { The general trend of ozone and hydroxyl radical } \\
\text { reactivity with the selected micropollutants was } \\
\text { explained. Suitable technology for the removal of } \\
\text { these micropollutants was suggested based on the } \\
\text { micropollutant reactivity with ozone and } \\
\text { hydroxyl radical. }\end{array}$ \\
\hline
\end{tabular}

$\mathrm{O}_{3}$, UV photolysis,

$\mathrm{O}_{3} / \mathrm{UV}, \mathrm{O}_{3}$ /catalyst,

[29]

UV/catalyst, $\quad$ Pyruvic acid

$\mathrm{H}_{2} \mathrm{O}_{2} / \mathrm{UV}$,

$\mathrm{H}_{2} \mathrm{O}_{2} / \mathrm{UV} /$ catalyst

[30]

$\mathrm{UV}, \mathrm{UV} / \mathrm{H}_{2} \mathrm{O}_{2}, \mathrm{UV} / \mathrm{O}_{3}$, $\mathrm{UV} / \mathrm{H}_{2} \mathrm{O}_{2} / \mathrm{O}_{3}$, p-Chlorophenol $\mathrm{UV} /$ Fenton

[31] $\mathrm{O}_{3}, \mathrm{H}_{2} \mathrm{O}_{2} / \mathrm{O}_{3}$, $\mathrm{UV} / \mathrm{Fe}^{2+} / \mathrm{H}_{2} \mathrm{O}_{2}$

[32]

$\mathrm{O}_{3} / \mathrm{UV}, \mathrm{H}_{2} \mathrm{O}_{2} / \mathrm{UV}$,

$\mathrm{O}_{3} / \mathrm{H}_{2} \mathrm{O}_{2}$

$\mathrm{O}_{3} / \mathrm{H}_{2} \mathrm{O}_{2} / \mathrm{UV}$

[33]

$\mathrm{O}_{3}, \mathrm{O}_{3} / \mathrm{UV}, \mathrm{O}_{3} / \mathrm{H}_{2} \mathrm{O}_{2}$,

$$
\mathrm{UV} / \mathrm{H}_{2} \mathrm{O}_{2} \text {, }
$$

$\mathrm{O}_{3} / \mathrm{UV} / \mathrm{H}_{2} \mathrm{O}_{2}$

O-Nitrotoluene

Nitroaromatics such as nitrotoluene, dinitrotoluene, and trinitrotoluene

Haloacetic acids (HAAs),

dichloroacetic acid (DCAA), and

trichloroacetic acid

(TCAA)

$\begin{array}{ll}\mathrm{O}_{3}, \mathrm{UV} \text {-vis, } & \text { Phenol, } \\ \mathrm{O}_{3}+\mathrm{UV} \text {-vis, } \mathrm{TiO}_{2}+ & \text { 4-nitrophenol, and } \\ \mathrm{UV} \text {-vis, } \mathrm{O}_{3}+\mathrm{UV} \text {-vis }+ & \text { 4-chlorophenol } \\ \mathrm{TiO}_{2} \text {, and } \mathrm{O}_{3}+\mathrm{TiO}_{2} & \end{array}$

[34]

$\mathrm{TiO}_{2}$, and $\mathrm{O}_{3}+\mathrm{TiO}_{2}$

[35]
$\mathrm{O}_{3}, \mathrm{O}_{3} / \mathrm{H}_{2} \mathrm{O}_{2}$,

$\mathrm{O}_{3}$ /activated carbon
Acid Blue 92 (AB92)
The UV/ $\mathrm{H}_{2} \mathrm{O}_{2}$ process with or without perovskite catalysts facilitates pyruvic acid removal fastest. The $\mathrm{O}_{3} / \mathrm{UV} /$ perovskite process was efficient for mineralization.

Operating conditions such as initial $\mathrm{pH}$, concentration of $\mathrm{H}_{2} \mathrm{O}_{2}$, and ferrous salt were optimized for each process. The UV/Fenton and $\mathrm{UV} / \mathrm{H}_{2} \mathrm{O}_{2} / \mathrm{O}_{3}$ processes were found to be the most effective for the degradation and mineralization of $p$-CP.

Ozonation and/or Fenton's reagent were found to be efficient for TNT degradation. The $\mathrm{O}_{3} / \mathrm{H}_{2} \mathrm{O}_{2}$ process at $\mathrm{pH}>7$ was most efficient for 2-MNT and 2.4-DNT removal.

The $\mathrm{O}_{3} / \mathrm{UV}$ process was the most efficient of the six degradation methods for DCAA and TCAA in water. Decomposition by AOPs was easier for DCAA than for TCAA.

The optimum $\mathrm{H}_{2} \mathrm{O}_{2}$ dosage and solution $\mathrm{pH}$ were studied. Adding $\mathrm{H}_{2} \mathrm{O}_{2}$ to the ozonation process accelerated the oxidation of $\mathrm{O}$-nitrotoluene by a factor of 8 . The $\mathrm{O}_{3} / \mathrm{UV}$ and $\mathrm{UV} / \mathrm{H}_{2} \mathrm{O}_{2}$ processes are 20 and 10 times more efficient than the ozonation process, respectively.

AOP efficiencies are in the following order: adsorption $<\mathrm{TiO}_{2}+\mathrm{UV}$-vis $<\mathrm{UV}$-vis $<\mathrm{O}_{3}+$ $\mathrm{TiO}_{2} \approx \mathrm{O}_{3}<\mathrm{O}_{3}+\mathrm{UV}$-vis $\approx \mathrm{O}_{3}+\mathrm{UV}$-vis $+\mathrm{TiO}_{2}$. The $\mathrm{O}_{3}+\mathrm{UV}$-vis and $\mathrm{O}_{3}+\mathrm{UV}$-vis $+\mathrm{TiO}_{2}$ methods are the most economically attractive.

Ozone treatment was a very effective method for complete removal of colour but in COD removal it was not efficient. The removal of COD in ozonation, $\mathrm{O}_{3} / \mathrm{H}_{2} \mathrm{O}_{2}$, and $\mathrm{O}_{3} / \mathrm{AC}$ processes, $30 \%$, $80 \%$ and $100 \%$, respectively. 
TABLE 2: Continued.

\begin{tabular}{|c|c|c|c|}
\hline Reference & AOPs applied & Pollutant(s) & Conclusions \\
\hline [36] & $\begin{array}{l}\mathrm{O}_{3} \text { or } \mathrm{O}_{3} / \mathrm{H}_{2} \mathrm{O}_{2} \\
\mathrm{O}_{3} / \text { powdered activated } \\
\text { carbon }(\mathrm{PAC})\end{array}$ & $\begin{array}{l}\text { Sodium } \\
\text { Dodecylbenzenesulfonate(SDBS) }\end{array}$ & $\begin{array}{l}\text { Comparison of the } \mathrm{O}_{3} / \text { PAC system with the } \mathrm{O}_{3} \\
\text { and } \mathrm{O}_{3} / \mathrm{H}_{2} \mathrm{O}_{2} \text { processes showed that the } \mathrm{O}_{3} / \mathrm{PAC} \\
\text { system was more effective in the removal of SDBS. }\end{array}$ \\
\hline [37] & $\mathrm{O}_{3}, \mathrm{O}_{3} / \mathrm{UV}, \mathrm{UV} / \mathrm{H}_{2} \mathrm{O}_{2}$ & Dye house effluent & $\begin{array}{l}\text { The AOP efficiency is dependent on the } \mathrm{pH} \text { and } \\
\text { dosage of } \mathrm{H}_{2} \mathrm{O}_{2} \text {. The } \mathrm{UV} / \mathrm{H}_{2} \mathrm{O}_{2} \text { process is } 50 \text { times } \\
\text { more efficient than the } \mathrm{O}_{3} / \mathrm{H}_{2} \mathrm{O}_{2} \text { process. }\end{array}$ \\
\hline [38] & $\begin{array}{l}\text { Ozonation, sonication, } \\
\text { UV photolysis, } \\
\mathrm{O}_{3} / \text { ultrasound, } \\
\text { UV/ultrasound, } \\
\mathrm{O}_{3} / \mathrm{UV} / \text { ultrasound }\end{array}$ & Phenol & $\begin{array}{l}\text { The efficiency of the various AOPs at two different } \\
\mathrm{pH} \text { was in the following order. At } \mathrm{pH} 2, \\
\mathrm{US} / \mathrm{UV} / \mathrm{O}_{3} \gg \mathrm{O}_{3} / \mathrm{UV}>\mathrm{US} / \mathrm{O}_{3}>\mathrm{US} / \mathrm{UV}>\mathrm{O}_{3}> \\
\mathrm{US}>\mathrm{UV} \text {. } \\
\text { At } \mathrm{pH} 10.0, \mathrm{US} / \mathrm{UV} / \mathrm{O}_{3}>\mathrm{O}_{3} / \mathrm{UV}>\mathrm{O}_{3}>\mathrm{US} / \mathrm{O}_{3}> \\
\mathrm{US} / \mathrm{UV}>\mathrm{UV}>\mathrm{US} \text {. The maximum rate of phenol } \\
\text { degradation was observed in the combined } \\
\text { application of } \mathrm{O}_{3} / \mathrm{UV} / \mathrm{US} \text { at basic } \mathrm{pH} \text {. }\end{array}$ \\
\hline [39] & $\begin{array}{l}\mathrm{US} \\
\mathrm{O}_{3} \\
\mathrm{O}_{3} / \mathrm{US} \\
\mathrm{O}_{3} / \mathrm{UV} \\
\mathrm{US} / \mathrm{UV} \\
\mathrm{O}_{3} / \mathrm{US} / \mathrm{UV}\end{array}$ & Acid Orange 7 & $\begin{array}{l}\text { The UV/O } / 3 \text { process was more effective at all times } \\
\text { than the US and/or } \mathrm{O}_{3} \text { process. The } \mathrm{O}_{3} / \mathrm{US} / \mathrm{UV} \\
\text { process was the most efficient for colour and } \\
\text { aromatic removal and } \mathrm{AO} 7 \text { dye mineralization. }\end{array}$ \\
\hline
\end{tabular}

with organic substrate at low $\mathrm{pH}$ as a molecular form, but at high $\mathrm{pH}$ it decomposes before reacting with the substrate. Ozone decomposition is catalyzed by hydroxide ions and proceeds more rapidly with increasing $\mathrm{pH}$, eventually to produce hydroxyl radicals. The influence of solution $\mathrm{pH}$ on ozonation process efficiency has been observed in a number of studies. For example, Jung et al. investigated the effect of $\mathrm{pH}$ on the ozonation of ampicillin from $\mathrm{pH} 5$ to 9, concluding that higher $\mathrm{pH}$ conditions are necessary for effective removal [66]. They also discussed how changing $\mathrm{pH}$ influences the charge of some specific functional groups on the ozonation process. Can and Gurol investigated the effect of solution $\mathrm{pH}$ on the ozonation of humic substances. They found that rapid ozone decomposition was caused by the interaction of ozone with the humic substance, which eventually yielded hydroxyl radical [67]. They further noted that increasing humic substance concentration facilitates fast ozone decomposition into hydroxyl radical. Similarly, the influence of solution $\mathrm{pH}$ and temperature on the ozonation of six dichlorophenols was investigated by Qiu et al. [68]. They revealed that the changing solution $\mathrm{pH}$ was strongly influenced the decomposition and the rate was increased by raising the hydroxyl radical concentration from acidic to alkaline $\mathrm{pH}$ [68].

Although hydroxyl radical formation is highly favourable to produce more ${ }^{\circ} \mathrm{OH}$ radicals by ozone self-decomposition at $\mathrm{pH} 10$, a portion of carbonate or bicarbonate ion formation could play a key scavenging role in trapping ${ }^{\circ} \mathrm{OH}$ radicals, appreciably decreasing the degradation rate. Wu et al. found that 2-propanol degradation decreases at $\mathrm{pH} 10$ and suggested bicarbonate formation as the possible reason for the decreasing degradation rate at this $\mathrm{pH}$ [19]. Other studies reached quite different results. Moussavi and Mahmoudi noted a higher removal rate of Reactive Red 198 azo dye in an ozonation process at $\mathrm{pH} 10$ [69]. Interestingly, Begum and
Gautam noted that as the $\mathrm{pH}$ increased from 9 to 12 in the ozonation process the endosulfan and lindane removal rate also increased [70]. In contrast to the above results other authors noted that the oxidation rate is relatively independent of solution $\mathrm{pH}$ values [71]. Hong and Zeng found that the rates of pentachlorophenol decomposition were very similar between $\mathrm{pH} 7$ and 12 , indicating then negligible influence of $\mathrm{pH}$ values [72]. These results clearly showed that the nature of pollutants being used for the ozonation process played an important role besides the favourable hydroxyl radical formation at higher $\mathrm{pH}$. Based on the above discussion it is concluded that the influence of $\mathrm{pH}$ on the ozonation process needs to be optimized.

Several investigations were conducted into the effect of temperature on the ozonation process. Changing the temperature generally influences the ozonation process in two ways. Firstly, when the temperature increases, the solubility of ozone may decrease, since Henry's law coefficient of ozone increases with rising temperatures. Secondly, raising the temperature increases the activation energy which may positively assist the ozonation process. Muruganandham et al. noted that $\mathrm{N}$-methyl pyrrolidone (NMP) mineralization was substantially increased when the ozonation temperature rose from 5 to $50^{\circ} \mathrm{C}[13]$. They also concluded that the increasing removal rate due to the higher reaction temperature is not balanced by the lower solubility of ozone. Similar results were noted in other ozonation studies $[68,73-76]$. Some researchers found, however, that increasing temperature in the ozonation process decreases the removal rate by decreasing the ozone solubility [77, 78]. Interestingly, $\mathrm{Ku}$ et al. found that the reaction rates of phorate decomposition were relatively independent of solution temperatures and $\mathrm{pH}$ values [71]. Yet some mineralization formation of products such as phosphate and carbonate was increased significantly with raised solution temperature. 
Another important experimental parameter influencing ozonation process efficiency is influent ozone dosage. Treatment cost increases with a higher applied ozone dose, so it is necessary to optimize this dosage. For semibatch experiments, increasing the ozone dosage will enhance the mass transfer rate of ozone from the gas phase to the liquid phase, which is expected to enhance the degradation rate appreciably. As the ozone concentration in the liquid phase is saturated, however, ozone mass transfer is limited at a very high ozone dosage [79]. Many authors investigated how the influent ozone dosage affects the degradation rate in the ozonation process within different experimental parameters. Muruganandham et al. reported that the optimal ozone dosage for NMP mineralization is $18.4 \mathrm{mg} \mathrm{min}^{-1}$ [13]. Moreover, an ozone dosage of $27.6 \mathrm{mg} \mathrm{min}^{-1}$ was noted as optimum for the degradation of dimethyl sulphoxide (DMSO) [80]. Begum and Gautam reported an optimum ozone dosage of $57 \mathrm{mg} \mathrm{min}^{-1}$ for endosulfan and lindane degradation although a higher ozone dosage slightly increased the endosulfan decomposition [70]. Yet other studies reported a linear increase in removal efficiencies with ozone dosage [81]. The above discussion clearly indicates that ozone dosage needs to be optimized in an ozonation process and that a number of experimental factors could influence the removal rate.

Though the ozonation process is effective for treating some organic compounds, a key problem is the accumulation of refractory compounds which interfere with the mineralization of the organic matter present in water. Some compounds were even found to be refractory to the ozonation process $[15,82,83]$. To improve its efficiency, ozonation was therefore combined with other oxidants. The combination of single oxidants can offer very effective treatment by producing more hydroxyl radicals.

It was reported that ozone in the presence of UV light enhances the decomposition rate of pollutants present in wastewater. The hydroxyl radicals generated in the $\mathrm{UV} / \mathrm{O}_{3}$ process are shown in (2). Decomposition may proceed in three different ways: (i) by ozonation, (ii) by direct UV photolysis, and (iii) by photolysis of ozone which generates hydroxyl radicals. The detail of the ozone photolysis mechanism is shown in (6)-(10) [84]. These combined processes should synergistically accelerate the degradation rate in the $\mathrm{UV} / \mathrm{O}_{3}$ process compared to the ozonation process. Many authors found that the $\mathrm{UV} / \mathrm{O}_{3}$ process is more efficient than ozonation in organic compounds degradation and mineralization [85-88]:

$$
\begin{gathered}
\mathrm{O}_{3}+h v \longrightarrow \mathrm{O}(1 \mathrm{D})+\mathrm{O}_{2} \\
\mathrm{O}(1 \mathrm{D})+\mathrm{H}_{2} \mathrm{O} \longrightarrow \mathrm{H}_{2} \mathrm{O}_{2} \text { (hot) } \\
\mathrm{H}_{2} \mathrm{O}_{2} \text { (hot) } \longrightarrow 2^{\circ} \mathrm{OH} \\
\mathrm{H}_{2} \mathrm{O}_{2} \text { (hot) }-\mathrm{H} \longrightarrow 2 \mathrm{H}_{2} \mathrm{O}_{2} \\
\mathrm{H}_{2} \mathrm{O}_{2}+h v \longrightarrow 2^{\bullet} \mathrm{OH}
\end{gathered}
$$

Recent studies also combined $\mathrm{H}_{2} \mathrm{O}_{2}$, and $\mathrm{TiO}_{2}$ with the $\mathrm{UV} / \mathrm{O}_{3}$ process [89-91]. These processes are more efficient than $\mathrm{O}_{3} / \mathrm{UV}$ alone due to their synergistic effect. The dosage of $\mathrm{H}_{2} \mathrm{O}_{2}$ in the $\mathrm{O}_{3} / \mathrm{H}_{2} \mathrm{O}_{2}$ process needs to be optimized, however. For example, Medellin-Castillo et al. studied diethyl phthalate degradation using the $\mathrm{O}_{3} / \mathrm{H}_{2} \mathrm{O}_{2}$ process with 0.45 to $1.80 \mathrm{mM}$ of $\mathrm{H}_{2} \mathrm{O}_{2}$, noting a linear relation with the degradation rate [25]. Kwon et al. studied 1,4-dioxane degradation with $\mathrm{H}_{2} \mathrm{O}_{2} / \mathrm{O}_{3}(w / w)$ ratios of $0,0.25,0.5,0.75,1,1.25$, and 1.5. They found the optimum dosage ratio to be 0.5 and noted a strong retardation effect at a ratio of 1.5 [26]. Similar results were also reported by Kusic et al. for the mineralization of phenol [27]. This could be because an excess of hydrogen peroxide could react with the hydroxyl radical produced during the decomposition process as shown in (11) and (12). So the $\mathrm{H}_{2} \mathrm{O}_{2}$ dosage needs to be optimized in the degradation process. Many authors have used various combined AOPs for pollutant degradation and their conclusions are summarized in Table 2. Consider

$$
\begin{gathered}
\mathrm{H}_{2} \mathrm{O}_{2}+\mathrm{OH} \longrightarrow \mathrm{H}_{2} \mathrm{O}+\mathrm{HO}_{2}{ }^{\bullet} \\
\mathrm{HO}_{2}{ }^{\bullet}+{ }^{\circ} \mathrm{OH} \longrightarrow \mathrm{H}_{2} \mathrm{O}+\mathrm{O}_{2}
\end{gathered}
$$

The presence of transition metal ions such as $\mathrm{Mn}^{2+}$, $\mathrm{Co}^{2+}, \mathrm{Ag}^{+}$, and $\mathrm{Fe}^{2+}$ in the ozonation process has significant catalytic effects in producing hydroxyl radical [92, 93]. Abd El-Raady and Nakajima studied the degradation of formic, oxalic, and maleic acids in the presence of first row transition metal ions such as $\mathrm{Co}^{2+}, \mathrm{Ni}^{2+}, \mathrm{Mn}^{2+}, \mathrm{Cu}^{2+}$, $\mathrm{Zn}^{2+}, \mathrm{Cr}^{3+}$, and $\mathrm{Fe}^{2+}$ and compared the process efficiency with the $\mathrm{O}_{3}$ and $\mathrm{O}_{3} / \mathrm{H}_{2} \mathrm{O}_{2}$ processes [93]. They concluded that the presence of $\mathrm{Co}^{2+}$ and $\mathrm{Mn}^{2+}$ ions has the highest catalytic activity for the decomposition of oxalic acid and that $\mathrm{O}_{3} / \mathrm{Co}^{2+}$ and $\mathrm{O}_{3} / \mathrm{Mn}^{2+}$ are more efficient than the $\mathrm{O}_{3} / \mathrm{H}_{2} \mathrm{O}_{2}$ process. Similarly, Cortes et al. reported that the $\mathrm{O}_{3} / \mathrm{Mn}^{2+}$ and $\mathrm{O}_{3} / \mathrm{Fe}^{2+}$ processes were more effective in the removal of organochloride compounds than the $\mathrm{O}_{3} / \mathrm{Fe}^{3+}$ and $\mathrm{O}_{3} /$ high $\mathrm{pH}$ systems [92]. Beltrán et al. found that the presence of $\mathrm{Co}^{2+}$ in water significantly enhances the ozonation rate of oxalic acid at acidic $\mathrm{pH}$ and that catalytic ozonation proceeds through the formation of a $\mathrm{Co}\left(\mathrm{HC}_{2} \mathrm{O}_{4}\right)_{2}$ complex [94]. Heterogeneous catalytic ozonation has received increasing attention due to its potentially higher effectiveness in the degradation of recalcitrant pollutants [95-101].

\section{Fenton and Photo-Fenton Based AOPs}

3.1. Fenton Reaction. The Fenton process has its root in the finding reported in 1894 that ferrous ion strongly elevated the oxidation of tartaric acid by hydrogen peroxide [102]. In the Fenton process, hydrogen peroxide is added to wastewater in the presence of ferrous salts, generating species that are strongly oxidative with respect to organic compounds. ${ }^{\bullet} \mathrm{OH}$ is traditionally regarded as the key oxidizing species in Fenton processes. The Fenton process mechanism is quite complex and is described in detail with equations in the literature [103, 104]. In summary, the classic Fenton free radical mechanism 


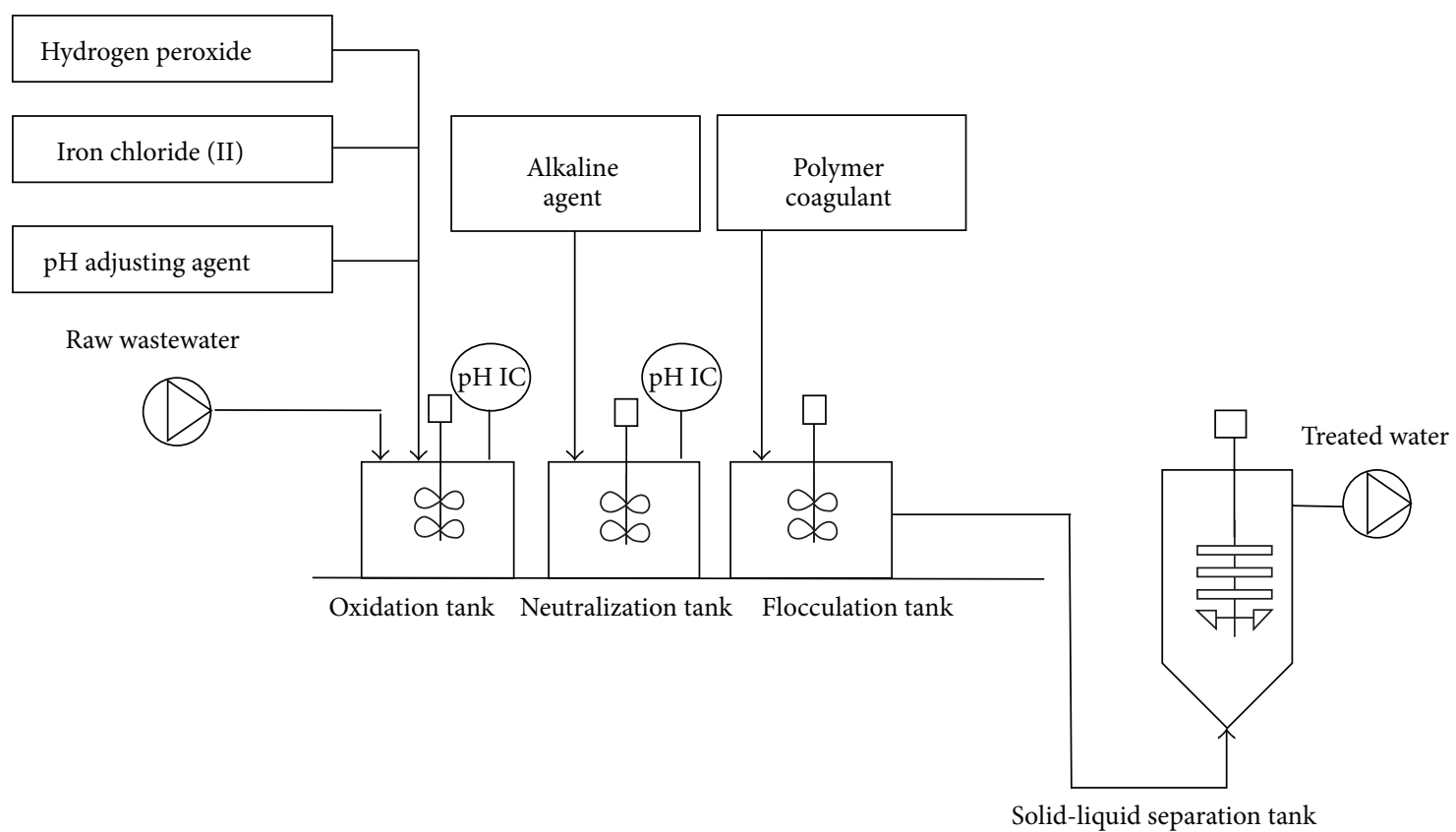

Figure 2: Treatment flow sheet for Fenton oxidation [123].

in the absence of organic compounds mainly involves the following sequence of reactions $[102,105]$ :

$$
\begin{gathered}
\mathrm{Fe}^{2+}+\mathrm{H}_{2} \mathrm{O}_{2} \longrightarrow \mathrm{Fe}^{3+}+\mathrm{OH}^{\circ} \mathrm{OH}^{-} \\
\mathrm{Fe}^{3+}+\mathrm{H}_{2} \mathrm{O}_{2} \longrightarrow \mathrm{Fe}^{2+}+\mathrm{HO}_{2}{ }^{+}+\mathrm{H}^{+} \\
\mathrm{OH}+\mathrm{H}_{2} \mathrm{O}_{2} \longrightarrow \mathrm{HO}_{2}{ }^{+}+\mathrm{H}_{2} \mathrm{O} \\
\cdot \mathrm{OH}+\mathrm{Fe}^{2+} \longrightarrow \mathrm{Fe}^{3+}+\mathrm{OH}^{-} \\
\mathrm{Fe}^{3+}+\mathrm{HO}_{2} \cdot \mathrm{Fe}^{2+}+\mathrm{O}_{2} \mathrm{H}^{+} \\
\mathrm{Fe}^{2+}+\mathrm{HO}_{2}{ }^{+}+\mathrm{H}^{+} \longrightarrow \mathrm{Fe}^{3+}+\mathrm{H}_{2} \mathrm{O}_{2} \\
2 \mathrm{HO}_{2} \longrightarrow \mathrm{H}_{2} \mathrm{O}_{2}+\mathrm{O}_{2}
\end{gathered}
$$

- $\mathrm{OH}$ radicals are rapidly generated through (14). In the above reactions, iron cycles between $\mathrm{Fe}^{2+}$ and $\mathrm{Fe}^{3+}$ and plays the role of catalyst. The net reaction of (14)-(20) is the decomposition of $\mathrm{H}_{2} \mathrm{O}_{2}$ into water and $\mathrm{O}_{2}$ catalyzed by iron as follows (21):

$$
2 \mathrm{H}_{2} \mathrm{O}_{2} \longrightarrow 2 \mathrm{H}_{2} \mathrm{O}+\mathrm{O}_{2}^{\cdot}
$$

As iron(II) acts as a catalyst, it has to be regenerated, which seems to occur through the following scheme [102]

$$
\begin{gathered}
\mathrm{Fe}^{3+}+\mathrm{H}_{2} \mathrm{O}_{2} \rightleftharpoons \mathrm{Fe}-\mathrm{OOH}^{2+}+\mathrm{H}^{+} \\
\mathrm{Fe}-\mathrm{OOH}^{2+} \longrightarrow \mathrm{Fe}^{2+}+\mathrm{HO}_{2}
\end{gathered}
$$

Generally speaking, Fenton's oxidation process is composed of four stages including $\mathrm{pH}$ adjustment, oxidation reaction, neutralization and coagulation, and precipitation.
The organic substances are removed at two stages of oxidation and coagulation $[106,107] .{ }^{\circ} \mathrm{OH}$ radicals are responsible for oxidation, and coagulation is ascribed to the formation of ferric hydroxo complexes [107, 108]. The relative importance of oxidation and coagulation depends primarily on the $\mathrm{H}_{2} \mathrm{O}_{2} / \mathrm{Fe}^{2+}$ ratio. Chemical coagulation predominates at a lower $\mathrm{H}_{2} \mathrm{O}_{2} / \mathrm{Fe}^{2+}$ ratio, whereas chemical oxidation is dominant at higher $\mathrm{H}_{2} \mathrm{O}_{2} / \mathrm{Fe}^{2+}$ ratios $[107,109]$. Wang et al. [110] and Lau et al. [111] reported that, in Fenton treatment of biologically stabilized leachate, oxidation and coagulation were responsible for approximately $20 \%$ and $80 \%$ of overall COD, removal respectively. Fenton oxidation has been tested with a variety of synthetic wastewaters containing a diversity of target compounds, such as phenols [112-114], chlorophenols [115], formaldehyde [116], 2,4-dinitrophenol [116], 2,4,6-trinitrotoluene [117], 2,4-dinitrotoluene, chlorobenzene, tetrachloroethylene [118], halomethanes, amines, and hexahydro-1,3,5-trinitro-1,3,5triazine (RDX) [119]. Many chemicals are refractory to Fenton oxidation, however, such as acetic acid, acetone, carbon tetrachloride, methylene chloride, oxalic acid, maleic acid, malonic acid, n-paraffins, and trichloroethane [116]. It has been demonstrated that these compounds are resistant under the usual mild operating conditions of Fenton oxidation $[114,120,121]$. In addition to these basic studies, the process has been applied to industrial wastewaters (such as chemical, pharmaceutical, textile, paper pulp, cosmetic, and cork processing wastewaters), sludge, and contaminated soils [122] resulting in significant reductions of toxicity, improvement of biodegradability, and colour and odour removal [116].

The oxidation rate was influenced by many factors such as $\mathrm{pH}$ value, $\mathrm{Fe}^{2+}: \mathrm{H}_{2} \mathrm{O}_{2}$ ratio, and the amount of iron salt. Some 
of these parameters are discussed in detail in the following sections. The Fenton process seems to be the best compromise because it is technologically simple, there is no mass transfer limitation (homogeneous nature), and both iron and hydrogen peroxide are cheap and nontoxic. From the economic point of view, using the Fenton process as a pretreatment can lower the cost and improve biological treatment efficiency [107].

A batch Fenton reactor essentially consists of a pressurized stirred reactor with metering pumps for the addition of acid, a base, a ferrous sulphate catalyst solution and industrial strength (35-50\%) hydrogen peroxide. It is recommended that the reactor vessel be coated with an acid resistant material, because Fenton's reagent is very aggressive and corrosion can be a serious problem. The $\mathrm{pH}$ of the solution must be adjusted to maintain the stability of the catalyst, as at pH 6 iron hydroxide is usually formed. For many chemicals the ideal $\mathrm{pH}$ for the Fenton reaction is between 3 and 4 , and the optimum catalyst to peroxide ratio is usually 1:5 wt/wt. Reactants are added in the following sequence: wastewater followed by dilute sulphuric acid catalyst in acidic solutions, base or acid for the adjustment of $\mathrm{pH}$ at a constant value, and lastly hydrogen peroxide (which must be added slowly, maintaining a steady temperature). Since wastewater compositions are highly changeable, there are some design considerations to enable the Fenton reactor to operate within flexible parameters. The discharge from the Fenton reactor is fed into a neutralizing tank to adjust the $\mathrm{pH}$ of the stream, followed by a flocculation tank and a solid-liquid separation tank for adjusting the TDS (total dissolved solids) content of the effluent stream. A schematic representation of the Fenton oxidation treatment is shown in Figure 2 [123].

As mentioned above, Fenton oxidation was applied to wastewater treatment based on the following observed optimum $\mathrm{pH}$ conditions, since this has been shown to affect the degradation of pollutants significantly $[106,124,125]$. The best value $\mathrm{pH}$ has been observed to be $2.8-3$ in the majority of cases; $[116,126,127]$, hence this is the recommended operating $\mathrm{pH}$. At lower $\mathrm{pH}(\mathrm{pH}=2.5)$, the formation of $\left(\mathrm{Fe}(\mathrm{II})\left(\mathrm{H}_{2} \mathrm{O}\right)\right)^{2+}$ occurs, which reacts more slowly with hydrogen peroxide, producing a smaller amount of reactive hydroxyl radicals by reducing the degradation efficiency [123].

Furthermore, the scavenging effect of hydroxyl radicals by hydrogen ions becomes important at a very low $\mathrm{pH}$, at which the reaction of $\mathrm{Fe}^{3+}$ with hydrogen peroxide is also inhibited. At an operating $\mathrm{pH}$ of $>3$, the decomposition rate decreases because of the decreased free iron species in the solution, probably due to the formation of $\mathrm{Fe}$ (II) complexes with the buffer inhibiting the formation of free radicals. At a $\mathrm{pH}$ higher than $3, \mathrm{Fe}^{3+}$ starts precipitating as ferric oxyhydroxides and breaks down the $\mathrm{H}_{2} \mathrm{O}_{2}$ into $\mathrm{O}_{2}$ and $\mathrm{H}_{2} \mathrm{O}[124,128]$, inhibiting the generation of ferrous ions. Additionally, the oxidation potential of ${ }^{\bullet} \mathrm{OH}$ radical is known to decrease with an increase in $\mathrm{pH}$ [123].

Usually the rate of degradation increases with an increased concentration of ferrous ions [125], though the increase is sometimes observed to be marginal above a certain concentration $[106,129]$. Additionally, an enormous increase in ferrous ions will lead to an increased unutilized quantity of iron salts, contributing to increased TDS content in the effluent treatment, which is not permitted. Thus laboratory scale studies are required to establish the optimum loading of ferrous ions under similar conditions, unless data are available in the open access literature [123].

The concentration of hydrogen peroxide plays a more crucial role in the overall efficacy of the degradation process. Usually it has been observed that the percentage degradation of the pollutant increases with an increased dosage of hydrogen peroxide $[106,129]$. Care should be taken however in selecting the operating oxidant dosage. The residual hydrogen peroxide contributes to COD, so an excess amount is not recommended. The presence of hydrogen peroxide is also harmful to many microorganisms and affects the overall degradation efficiency significantly where Fenton oxidation is used as a pretreatment to biological oxidation. One more negative effect of hydrogen peroxide, if present in large quantities, is that it acts as a scavenger for the generated hydroxyl radicals. Thus hydrogen peroxide loading should be adjusted so that the entire amount is utilized. This can be decided based on laboratory scale studies with the effluent in question [123].

It should be noted that the dose of $\mathrm{H}_{2} \mathrm{O}_{2}$ and the concentration of $\mathrm{Fe}^{2+}$ are two relevant and closely related factors affecting the Fenton process. The $\mathrm{H}_{2} \mathrm{O}_{2}$ dose has to be fixed according to the initial pollutant concentration. An amount of $\mathrm{H}_{2} \mathrm{O}_{2}$ corresponding to the theoretical stoichiometric $\mathrm{H}_{2} \mathrm{O}_{2}$ to chemical oxygen demand (COD) ratio is frequently used [116], although it depends on the response of the specific contaminants to oxidation and on the objective pursued in terms of reducing the contaminant load. Usually a lower initial pollutant concentration is favoured [125], but the negative effects of treating a large quantity of effluent need to be analyzed before the dilution ratio can be set. For real industrial wastes, some dilution is often essential before any degradation is observed using Fenton oxidation [123].

As noted above, as the maximum degradation rates are observed at a $\mathrm{pH}$ of approximately 3, the operating $\mathrm{pH}$ should be maintained constant around this optimum value. The type of buffer solution used also affects the degradation process [125]. Acetic acid/acetate buffer provides maximum oxidation efficiency, at least as observed for phosphate and sulphate buffers. This can be attributed to the formation of stable $\mathrm{Fe}^{3+}$ complexes under these conditions [123].

Not many studies are available depicting the effect of temperature on degradation rates and ambient conditions can safely be used with good efficiency [123]. Besides, reaction temperature is another crucial parameter in the Fenton process. In principle, increasing the temperature should enhance the kinetics of the process, but it also favours the decomposition of $\mathrm{H}_{2} \mathrm{O}_{2}$ towards $\mathrm{O}_{2}$ and $\mathrm{H}_{2} \mathrm{O}$. This increases at a rate of around 2.2 times each $10^{\circ} \mathrm{C}$ in the range of $20-100^{\circ} \mathrm{C}$ [130]. Oxidation with Fenton's reagent has already been proved effective and promising for the 
TABLE 3: Typical findings observed in work related to the use of Fenton.

\begin{tabular}{|c|c|c|c|}
\hline Reference & Process conditions & Pollutant(s) & Conclusions \\
\hline [40] & $\begin{array}{l}\text { A temperature controllable magnetic stirrer ensures } \\
\text { perfect mixing at a constant rate of } 300 \mathrm{rpm} \text { during all } \\
\text { experiments. The effect of } \mathrm{Fe}^{2+} \text { concentration on COD } \\
\text { removal varied in the range of } 0.5-10 \mathrm{mM} \text { (these } \\
\text { factors were kept constant: } \mathrm{H}_{2} \mathrm{O}_{2}=30 \mathrm{mM} \text {; } \mathrm{pH}=3 \text {; } \\
t=30 \mathrm{~min} \text {; } \mathrm{COD}=2741 \mathrm{mg} / \mathrm{L} \text { ). The selected } \mathrm{H}_{2} \mathrm{O}_{2} \\
\text { concentration was in the range of } 10-100 \mathrm{mM} \text { while } \\
\mathrm{pH}=3 \text { and } \mathrm{Fe}^{2+}=10 \mathrm{mM} \text { at } 30 \text { min. The tested pH } \\
\text { values ranged between } 2 \text { and } 5 \text {. }\end{array}$ & $\begin{array}{l}\text { Synthetic acid dye } \\
\text { baths (SADB) } \\
\text { consist of three } \\
\text { different acid } \\
\text { dyestuffs (C.I. } \\
\text { Acid Yellow 242, } \\
\text { C.I. Acid Red 360, } \\
\text { and C.I. Acid Blue } \\
\text { 264) and two dye } \\
\text { auxiliaries (a } \\
\text { levelling agent and } \\
\text { an acid donor) }\end{array}$ & $\begin{array}{l}\text { Optimum experimental conditions for the } \\
\text { simulated acid dye bath effluent were established as } \\
\text { follows: } \mathrm{Fe}^{2+}=10 \mathrm{mM}, \mathrm{H}_{2} \mathrm{O}_{2}=30 \mathrm{mM} \text {, and } \mathrm{pH}=3 \\
\text { at room temperature }\left(T=20^{\circ} \mathrm{C}\right) \text {, which yielded an } \\
\text { overall COD removal efficiency of } 23 \% \text {. The } \\
\text { corresponding colour removal efficiency was } 92 \% \\
\text { and the first-order COD abatement rate constant } \\
\text { increased from } 0.02 \mathrm{~min}^{-1} \text { to } 0.03 \mathrm{~min}^{-1} \text { by } \\
\text { increasing the temperature from } 20 \text { to } 50^{\circ} \mathrm{C} \text {. The } \\
\text { first-order reaction rate constant for } \\
\mathrm{H}_{2} \mathrm{O}_{2} \text { consumption increased from } 0.15 \mathrm{~min}^{-1} \text { to } \\
0.34 \text { min }{ }^{-1} \text { by increasing the temperature from } 20 \text { to } \\
50^{\circ} \mathrm{C} \text {. Further increases in temperature did not } \\
\text { improve oxidation and oxidant consumption rates. } \\
\mathrm{H}_{2} \mathrm{O}_{2} \text { consumption ran parallel to COD removal at } \\
\text { a rate approximately } 10 \text { times faster than COD } \\
\text { abatement. }\end{array}$ \\
\hline
\end{tabular}

The Fenton reactor was stirred at room temperature in an open-batch system with a magnetic stirring bar and was treated for $2 \mathrm{~h}$. The $\mathrm{Fe}^{+2}: \mathrm{H}_{2} \mathrm{O}_{2}$ ratio was RB49 Reactive Blue 49 varied in the range of $1: 5,1: 10,1: 20,1: 30,1: 40$, and RB137 Reactive $1: 50, \mathrm{pH}$ in the range of $2-4$, and $\mathrm{Fe}^{2+}$ in the range 0.5 Blue 137 and $1 \mathrm{mM}$.
The Fenton process was decolourized more than $90 \%$ in all cases. The best mineralization extent, that is, maximal TOC removal, $72.1 \%$, was obtained for degradation of RB49 by Fenton process, $\mathrm{Fe}^{2+}: \mathrm{H}_{2} \mathrm{O}_{2}$ $=1: 20, \mathrm{Fe}^{2+}=0.5 \mathrm{mM}$ at $\mathrm{pH}=3$. The molecular structure of the dyes studied plays a significant role in oxidation by Fenton type processes.

Fenton's process proved highly effective in the degradation of EDTA in spiked integrated wastewater. With an initial molar ratio of $70: 1$ $\left(\mathrm{H}_{2} \mathrm{O}_{2}\right.$ and EDTA) or higher, EDTA degradation was nearly complete within 3 min of reaction time. Lower EDTA degradation levels at $\mathrm{pH} 4$ and low temperature in bleaching effluent are a major drawback in this study. reaction and $\mathrm{pH}$ were fixed at $60^{\circ} \mathrm{C}$ and 3 , respectively.

Ethylenediamine tetra acetic acid (EDTA), novel complexing agents, namely, BCA5 and BCA6
The initial concentrations of Fe(II) used in this study were $8.37,13.95,19.53,25.11$, and $33.40 \mathrm{mg} / \mathrm{L}$, the $\mathrm{Fe}^{2+}: \mathrm{H}_{2} \mathrm{O}_{2}$ ratios were set at $0.016,0.028,0.039,0.05$ and 0.067 , and the concentration of $\mathrm{H}_{2} \mathrm{O}_{2}$ was kept constant at $500 \mathrm{mg} / \mathrm{L}$. The initial concentrations of $\mathrm{H}_{2} \mathrm{O}_{2}$ used in this study were $50,100,200,500$, and $700 \mathrm{mg} / \mathrm{L}$, the $\mathrm{Fe}^{2+}: \mathrm{H}_{2} \mathrm{O}_{2}$ ratios were set at 0.0199 , $0.0279,0.06975,0.1395$, and 0.279 , and the concentration of $\mathrm{Fe}(\mathrm{II})$ was fixed at $13.95 \mathrm{mg} / \mathrm{L}$.

All tests were conducted in a $200 \mathrm{~mL}$ double glass cylindrical jacketed reactor, which allows cycle water to maintain the reaction mixture at a constant temperature. Temperature control was realized through a thermostat and a magnetic stirrer was used to stir reaction solutions. Operating $\mathrm{pH}$ was in the range of 2.5-6.0 and decolouration time was $60 \mathrm{~min}$. Hydrogen peroxide in the range of $1.0 \times 10^{-3}$ to $4.0 \times 10^{-2} \mathrm{M}$ and the $\mathrm{Fe}^{2+}$ dosage on the decolourization of OG with different initial concentrations from $5.0 \times 10^{-6}$ to $3.5 \times 10^{-5} \mathrm{M}$. Reaction temperature was varied in the range of $20-50^{\circ} \mathrm{C}$. The effect of the presence of chloride ion $\left(2.82 \times 10^{-2}\right.$ to $\left.2.82 \times 10^{-1} \mathrm{M}\right)$ on the decolourization of OG was investigated. The decolourization of different concentrations of OG was studied in the range of $2.21 \times 10^{-5}$ to $1.66 \times 10^{-4} \mathrm{M}$.
The decolourization rate is strongly dependent on the initial concentrations of $\mathrm{Fe}^{2+}$ and $\mathrm{H}_{2} \mathrm{O}_{2}$. The

Azo dye C.I. Acid optimum operational conditions were obtained at

Yellow 23 (AY 23) pH 3. The results show that as much as $98 \%$ of AY 23 can be decolourized by $13.95 \mathrm{mg} / \mathrm{L}$ ferrous ions and $500 \mathrm{mg} / \mathrm{L} \mathrm{H}_{2} \mathrm{O}_{2}$.
Azo dye Orange $\mathrm{G}$ (OG)

The results showed a suitable decolourization condition of initial $\mathrm{pH} 4.0, \mathrm{H}_{2} \mathrm{O}_{2}$ dosage $1.0 \times 10^{-2} \mathrm{M}$, and molar ratio of $\left[\mathrm{H}_{2} \mathrm{O}_{2}\right] /\left[\mathrm{Fe}^{2+}\right]$ $286: 1$. The decolourization efficiencies within 60 min were more than $94.6 \%$. It was found that the decolourization efficiency of OG enhanced with increased reaction temperature but the presence of chloride ion had a negative impact on the decolourization of OG. The decolourization kinetics of OG by Fenton oxidation process followed the second-order reaction kinetics, and the apparent activation energy $E$ was detected to be $34.84 \mathrm{~kJ} / \mathrm{mol}$. 
TABLE 3: Continued.

\begin{tabular}{|c|c|c|}
\hline Reference & Process conditions & Pollutant(s) \\
\hline [45] & $\begin{array}{l}\text { Chemical oxidation of the red dye solutions with } \\
\text { Fenton's reagent was carried out in a closed jacketed } \\
\text { batch reactor ( } 1 \mathrm{~L} \text { capacity). The reactor was provided } \\
\text { with constant stirring, accomplished through a } \\
\text { magnetic bar and a Falc magnetic stirrer. The } \\
\text { temperature of the reaction mixture was kept constant } \\
\text { by coupling the reactor to a Huber thermostatic bath. } \\
\text { Operating pH and } \mathrm{H}_{2} \mathrm{O}_{2} \text { concentration were varied in } \\
\text { the range of } 2-5 \text { and } 5.9-8.8 \mathrm{mM} \text {, respectively. The } \\
\text { effect of the Fe } \mathrm{F}^{2+} \text { concentration and reaction } \\
\text { temperature was investigated in the range of } \\
0.13-1.1 \mathrm{mM} \text { and } 20-70^{\circ} \mathrm{C} \text {, respectively. }\end{array}$ & $\begin{array}{l}\text { Azo dye (Procion } \\
\text { Deep Red H-EXL } \\
\text { gran) }\end{array}$ \\
\hline
\end{tabular}

Fenton's reagent experiments were carried out at room temperature $\left(23 \pm 2^{\circ} \mathrm{C}\right)$ using different $\mathrm{H}_{2} \mathrm{O}_{2}$ and $\mathrm{Fe}$ (II) doses at $\mathrm{pH}$ 3.5. The percentage variation of simazine removal was investigated with $\mathrm{H}_{2} \mathrm{O}_{2}$ concentration at different simazine doses between 0.5 and $5.0 \mathrm{mg} / \mathrm{L}$ and at different $\mathrm{Fe}(\mathrm{II})$ doses between 5 and $30 \mathrm{mg} / \mathrm{L}$ at the end of a $6 \mathrm{~min}$ reaction time.

\section{Conclusions}

Total organic carbon (TOC) reduction occurred after $120 \mathrm{~min}$ of reaction; however, the reaction time required to achieve colour removal levels above $95 \%$ is around $15 \mathrm{~min}$. Four operating variables must be considered, namely, the $\mathrm{pH}$, the concentration of hydrogen peroxide, the temperature, and the concentration of ferrous ion, between 3-4, $5.9 \mathrm{mM}$, $20 \mathrm{~min}$, and $0.27 \mathrm{mM}$, respectively. It was concluded that temperature and ferrous ion concentration are the only-variables that affect TOC removal, and, due to cross interactions, the effect of each variable depends on the value of the other one, thus affecting the process response positively or negatively.

At a constant simazine concentration, the percentage of TOC removal increased with increasing $\mathrm{H}_{2} \mathrm{O}_{2}$ and $\mathrm{Fe}(\mathrm{II})$ concentrations up to $15 \mathrm{mg} / \mathrm{L} \mathrm{Fe}$ (II) and $50 \mathrm{mg} / \mathrm{L}$ peroxide above which mineralization decreased due to the scavenging effects of $\mathrm{H}_{2} \mathrm{O}_{2}$ on hydroxyl radicals. Maximum pesticide $(100 \%)$ and TOC removals $(32 \%)$ were obtained with $\mathrm{H}_{2} \mathrm{O}_{2} / \mathrm{Fe}(\mathrm{II}) /$ simazine ratio of $55: 15: 3(\mathrm{mg} / \mathrm{L})$. Simazine degradation was incomplete, yielding the formation of intermediates which were not completely mineralized to $\mathrm{CO}_{2}$ and $\mathrm{H}_{2} \mathrm{O}$.

Fenton oxidation is an effective method to transform TNT totally in contaminated aqueous solution. This is feasible by the efficient generation of hydroxyl radicals during $\mathrm{H}_{2} \mathrm{O}_{2}$ catalytic decomposition with $\mathrm{Fe}(\mathrm{II})$ ions. TNT degradation kinetics and efficiency are largely influenced by $\mathrm{H}_{2} \mathrm{O}_{2}$ and $\mathrm{Fe}^{2+}$ concentrations. Using $\left[\mathrm{H}_{2} \mathrm{O}_{2}\right]_{0}:[\mathrm{Fe}(\mathrm{II})]_{0}$ molar ratios equal to or lower than 0.5 leads to the formation of the maximum number of intermediates. The absolute rate constant of the reaction between hydroxyl radicals and TNT is $9.6-10 \times 10^{8} \mathrm{M}^{-1} \mathrm{~s}^{-1}$.

The Fenton reactor was a $0.5 \mathrm{~L}$ beaker placed in a thermostat water bath with constant temperature and stirred by a magnetic stirrer, with operating $\mathrm{pH}$ values of 2.50, 3.00, 3.50, 4.00, and 5.00, initial $\mathrm{H}_{2} \mathrm{O}_{2}$ concentration in the range of $0.10 \mathrm{mM}$ to $4.00 \mathrm{mM}$, initial concentration of $\mathrm{Fe}^{2+}$ from $0.01 \mathrm{mM}$ to

Azo dye Amido Black 10B
The optimal operation parameters for the Fenton oxidation of Amido Black 10B were $0.50 \mathrm{mM}$ $\left[\mathrm{H}_{2} \mathrm{O}_{2}\right]_{0}$ and $0.025 \mathrm{mM}\left[\mathrm{Fe}^{2+}\right]_{0}$ for $50 \mathrm{mg} / \mathrm{L}[\text { dye }]_{0}$ at an initial $\mathrm{pH}$ of 3.50 at a temperature of $25^{\circ} \mathrm{C}$. Under these conditions, $99.25 \%$ dye degradation efficiency in aqueous solution was achieved after $60 \mathrm{~min}$ of reaction. The Fenton treatment process showed that it was easier to destruct the $-\mathrm{N}=\mathrm{N}$-group than to destruct the aromatic rings of Amido Black 10B. on its degradation in the range of $10-100 \mathrm{mg} / \mathrm{L}$. A series of experiments were conducted by varying the temperature from $15^{\circ} \mathrm{C}$ to $45^{\circ} \mathrm{C}$.

Fenton oxidation was performed in a batch reactor under initially anaerobic conditions to determine the effect of $[\mathrm{MTBE}]_{0}$ on the degradation of MTBE with FR: MTBE degradation at different $[\mathrm{MTBE}]_{0}$ in the range of 1,2 , and $5 \mathrm{mg} / \mathrm{L}$ when treated with the same amount of FR. This study was performed using solutions containing $[\mathrm{MTBE}]_{0}$ of 11.4 and $22.7 \mathrm{mM}$, each one in individual experiments at $\mathrm{pH}$ values of 3.0, 3.6, 5.0, 6.3, and 7.0. The FR to MTBE molar ratio varied in the range of $0.5: 1$ and $200: 1$. The initial concentration of pollutant was $22.7 \mu \mathrm{M}$ and FR was used in a 1:1 molar ratio of ferrous iron $\left(\mathrm{Fe}^{2+}\right)$ and hydrogen peroxide $\left(\mathrm{H}_{2} \mathrm{O}_{2}\right)$ at $\mathrm{pH}=3$.
FR partially degraded low $[\mathrm{MTBE}]_{0}$ in water $(11.4$ and $22.7 \mu \mathrm{M}$ ). Experiments at acidic $\mathrm{pH}$ yielded the best results of MTBE degradation (>90\%), and

Methyl tert-butyl small differences were observed between the results ether (MTBE) at pH 3.0 and 5.0. The majority of MTBE degradation and generation of intermediates occurred during the initial phase and followed pseudo first-order kinetics. 
TABLE 3: Continued.

\begin{tabular}{|c|c|c|c|}
\hline Reference & Process conditions & Pollutant(s) & Conclusions \\
\hline$[50]$ & $\begin{array}{l}\text { The experiments were conducted in batch mode. } 4 \mathrm{~L} \\
\text { borosilicate reactors were filled with } 3.6 \mathrm{~L} \text { of deionized } \\
(\mathrm{DI}) \text { water at } \mathrm{pH}=3.0 \text { and purged with high-purity } \\
\text { nitrogen until the dissolved oxygen }(\mathrm{DO}) \text { reading was } \\
\text { below } 0.01 \mathrm{mg} / \mathrm{L} \text { and the oxygen concentration in the } \\
\text { head space was negligible }(\approx 0.01 \%) \text {. }\end{array}$ & $\begin{array}{l}\text { Methyl tert-butyl } \\
\text { ether (MTBE) }\end{array}$ & $\begin{array}{l}\text { The added amount of FR proved to be an important } \\
\text { controlling parameter for the overall MTBE } \\
\text { degradation mineralization efficiency. An FR to } \\
\text { MTBE molar ratio of } 20: 1 \text { was the minimum } \\
\text { required to achieve complete MTBE degradation. } \\
\text { Kinetic analysis is reported to be pseudo first-order } \\
\text { given the good linear correlation found between } k^{\prime} \\
\text { and FMMR. Other intermediates not identified in } \\
\text { this study are generated in significant } \\
\text { concentrations at these conditions. }\end{array}$ \\
\hline [51] & $\begin{array}{l}\text { A series of experiments were conducted at pH } 3 \text { for } 5 \text {, } \\
15 \text {, or } 60 \text { min of mixing followed by } 30 \text { min } \\
\text { clarification. The studied } \mathrm{H}_{2} \mathrm{O}_{2} / \mathrm{Fe}^{2+} \text { stoichiometric } \\
\text { molar ratios were } 1,2,3,4,5 \text {, and } 10 \text { with } \mathrm{H}_{2} \mathrm{O}_{2} \text { dose of } \\
1000 \mathrm{mgL}^{-1} \text {, and the } \mathrm{H}_{2} \mathrm{O}_{2} / \mathrm{Fe}^{2+} \text { stoichiometric molar } \\
\text { ratios were } 0.5,2,3,5 \text {, and } 10 \text { with } \mathrm{H}_{2} \mathrm{O}_{2} \text { dose of } \\
500 \mathrm{mgL}^{-1} \text {. A further series of experiments were } \\
\text { conducted at an initial pH of } 3,4,5,6 \text {, or } 7 \text { with } 5 \text { min } \\
\text { mixing followed by } 30 \text { min clarification. Comparisons } \\
\text { between the Fenton process and } \mathrm{Fe}^{3+} \text { coagulation were } \\
\text { carried out at an initial pH of } 3 \text { and } 7 \text {. }\end{array}$ & $\begin{array}{l}\text { Nuclear laundry } \\
\text { water }\end{array}$ & $\begin{array}{l}\text { The experimental data generally indicated } \\
\text { decreased removal efficiencies of organic } \\
\text { compounds with an increasing } \mathrm{H}_{2} \mathrm{O}_{2} / \mathrm{Fe}^{2+} \text { ratio. Yet } \\
\text { taking into account all factors, thermostat } \\
\text { cost-effective degradation conditions were at } \\
\mathrm{H}_{2} \mathrm{O}_{2} / \mathrm{Fe}^{2+} \text { stoichiometric molar ratio of } 2 \text { with } \\
5 \text { min mixing and an } \mathrm{H}_{2} \mathrm{O}_{2} \text { dose of } 1000 \mathrm{mgL}^{-1} \text {. The } \\
\text { initial pH of the laundry water can be as high as } 7 \text {. } \\
\mathrm{Fe}^{3+} \text { coagulation experiments were conducted in } \\
\text { order to interpret the nature of the Fenton process. } \\
\text { Since the removal efficiency of organic compounds } \\
\text { in the Fenton process was slightly higher than in } \\
\text { coagulation, the treatment of the nuclear laundry } \\
\text { water can be called Fenton-based Fe } \mathrm{Fe}^{3+} \text { coagulation. }\end{array}$ \\
\hline
\end{tabular}

destruction of several compounds and consequently for the treatment of a wide range of wastewaters, as described in several reviews (e.g. $[102,104,116,123,131,132])$. Table 3 summarizes recent Fenton processes for some wastewater treatments.

3.2. Photo-Fenton Processes. The photo-Fenton process, as its name suggests, is rather similar to the Fenton one but also employs radiation $[102,104,123,133]$. The photo-Fenton reaction is also well known in the literature $[104,134]$ as an efficient and inexpensive method of wastewater and soil treatment [104, 135]. Photo-Fenton process is known to be capable of improving the efficiency of dark Fenton or Fenton-like reagents by means of the interaction of radiation (UV or Vis) with Fenton's reagent [136]. This technique has been suggested as feasible and promising for removing pollutants from natural and industrial waters and increasing the biodegradability of chlorophenols when used as a pretreatment method to decrease water toxicity [104]. Some of its most innovative applications include oxalate as a ligand of iron ions [104, 137].

The effectiveness of photo-Fenton processes is attributed to the photolysis of $\mathrm{Fe}$ (III) cations in acidic media yielding $\mathrm{Fe}(\mathrm{II})$ cations (24), in conjunction with reaction between $\mathrm{Fe}(\mathrm{II})$ and ${ }^{\bullet} \mathrm{OH}$ to yield hydroxyl radicals (Fenton's reaction, step 24):

$$
\begin{gathered}
\mathrm{Fe}(\mathrm{OH})^{2+}+h v \longrightarrow \mathrm{Fe}^{2+}+{ }^{\cdot} \mathrm{OH} \\
\mathrm{Fe}^{2+}+\mathrm{H}_{2} \mathrm{O}_{2} \longrightarrow \mathrm{Fe}(\mathrm{OH})^{2+}+{ }^{\bullet} \mathrm{OH}
\end{gathered}
$$

In this process, the photolytic decomposition of $\mathrm{Fe}(\mathrm{OH})^{2+}(24)$ is accelerated, providing an additional source of highly oxidative hydroxyl radicals compared to the "simple" Fenton process [102]. The photo-Fenton process produces more hydroxyl radicals than the conventional Fenton method (Fe(II) with hydrogen peroxide) or photolysis, thus promoting organic pollutant degradation rates. This process consists of a combination of Fenton reagents $\left(\mathrm{Fe}^{2+} / \mathrm{H}_{2} \mathrm{O}_{2}\right)$ and light energy $[138,139]$ and thus of two reactions [136]:

$$
\begin{gathered}
\mathrm{Fe}^{2+}+\mathrm{H}_{2} \mathrm{O}_{2} \longrightarrow \mathrm{Fe}^{3+}+{ }^{\bullet} \mathrm{OH}+\mathrm{OH}^{-} \\
\mathrm{Fe}^{3+}+\mathrm{H}_{2} \mathrm{O}+h \nu \longrightarrow \mathrm{Fe}^{2+}+{ }^{\bullet} \mathrm{OH}+\mathrm{H}^{+}
\end{gathered}
$$

The first reaction is a reaction of $\mathrm{Fe}^{2+}$ with $\mathrm{H}_{2} \mathrm{O}_{2}$, which generates the powerful reactive species ${ }^{\circ} \mathrm{OH}$ radicals and oxidizes $\mathrm{Fe}^{2+}$ to $\mathrm{Fe}^{3+}$. In other words, the hydroxyl radical generation in Fenton processes is due to the iron catalyzed decomposition of $\mathrm{H}_{2} \mathrm{O}_{2}$. The first photo-Fenton reaction causes the formation of hydroxyl radicals. The second reaction of the photo-Fenton process is a reaction of $\mathrm{Fe}^{3+}$ with water, which occurs when light is used at a wavelength from $300 \mathrm{~nm}$ to $650 \mathrm{~nm}$. This generates ${ }^{\circ} \mathrm{OH}$ radicals and reduces $\mathrm{Fe}^{3+}$ to $\mathrm{Fe}^{2+}$. These two oxidation-reduction reactions occur repeatedly and completely mineralize organic pollutants to $\mathrm{CO}_{2}$ and $\mathrm{H}_{2} \mathrm{O}[136]$ :

$$
\begin{gathered}
\text { Pollutants }+{ }^{\circ} \mathrm{OH} \longrightarrow \text { Intermediates } \\
\text { Intermediates }+{ }^{\circ} \mathrm{OH} \longrightarrow \mathrm{CO}_{2}+\mathrm{H}_{2} \mathrm{O}
\end{gathered}
$$


TABLE 4: Typical findings observed in work related to the use of photo-Fenton.

\begin{tabular}{|c|c|c|c|}
\hline Reference & Process conditions & Pollutant(s) & Conclusions \\
\hline$[52]$ & $\begin{array}{l}\text { Natural } \mathrm{pH} \text { conditions with phenol } \\
\text { concentrations in the range of } 180-733 \mathrm{mg} / \mathrm{L} \text {. } \\
\text { The photochemical treatment was mediated } \\
\text { with ferrioxalate and peroxide in two } \\
\text { photoreactors of different volumes and } \\
\text { operation conditions (batch and with closed } \\
\text { flow). }\end{array}$ & Wastewater & $\begin{array}{l}\text { Phenol transformation efficiencies of } 100 \% \text { and } \\
\text { total COD reduction percentages of } 85 \% \text { were } \\
\text { reached within the first hour of phototreatment, } \\
\text { with an aromatic free effluent as the final product } \\
\text { in both types of reactor. The ferrioxalate type } \\
\text { complexes using mass ratios of oxalate/phenol = } \\
1.5 \text {, oxalate } / \mathrm{Fe}^{3+}=15 \text {, and } \mathrm{H}_{2} \mathrm{O}_{2} / \text { phenol }>5.0 \\
\text { were shown to be very effective in the treatment } \\
\text { of these effluents, even at pH conditions close to } \\
\text { neutral, the pH region in which Fenton type } \\
\text { processes begin to lose efficiency due to the } \\
\text { precipitation of iron as a hydroxide. }\end{array}$ \\
\hline [53] & $\begin{array}{l}\text { Photo-Fenton process in a CPC solar } \\
\text { photoreactor. The effect of solar activated } \\
\text { photo-Fenton reagent at } \mathrm{pH} 5.0 \text { before and } \\
\text { after a slow sand filtration (SSF) process in } \\
\text { waters containing natural iron species was } \\
\text { investigated. }\end{array}$ & $\begin{array}{l}\text { Natural organic } \\
\text { matter (NOM) } \\
\text { model compounds } \\
\text { (dihydroxy- } \\
\text { benzene) }\end{array}$ & $\begin{array}{l}\text { The results showed that the total transformation } \\
\text { of dihydroxybenzene compounds was obtained } \\
\text { with a mineralization of over } 80 \% \text {. The } \\
\text { mineralization of organic compounds dissolved } \\
\text { in natural water was higher than in Milli-Q } \\
\text { water, suggesting that the aqueous organic and } \\
\text { inorganic components (metals, humic acids, and } \\
\text { photoactive species) positively affect the } \\
\text { photocatalytic process. When } 1.0 \mathrm{mg} / \mathrm{L} \text { of } \mathrm{Fe}^{3+} \\
\text { was added to the system, photo-Fenton } \\
\text { degradation improved. }\end{array}$ \\
\hline
\end{tabular}

Two laboratory scale photo-Fenton experiments were performed with the solar simulator and SMX dissolved in diluted water (DW) and in seawater (SW) at the same concentration $(50 \mathrm{mg} / \mathrm{L}$; DOC $=23.75 \mathrm{mg} / \mathrm{L})$ as in the pilot plant experiments for their comparison with natural solar radiation. The initial DOC of SW was $2.6 \mathrm{mg} \mathrm{C/L}$. The experiments were performed at three different initial concentrations of $\mathrm{FeSO}_{4} \cdot 7 \mathrm{H}_{2} \mathrm{O}(2.6,5.2$, and $10.4 \mathrm{mg} / \mathrm{L})$. Initial $\mathrm{H}_{2} \mathrm{O}_{2}$ concentrations ranged from 30 to $210 \mathrm{mg} / \mathrm{L}$. The solar pilot plant reactor consisted of a compound parabolic collector (CPC) with a $3.0 \mathrm{~m}^{2}$ irradiated surface and total volume of $39 \mathrm{~L}$.

Photo-Fenton oxidation was carried out using a cylindrical Pyrex thermostatic cell with a $300 \mathrm{~mL}$ capacity $\left(T=23 \pm 1^{\circ} \mathrm{C}\right)$, equipped with a magnetic stirrer. The dye solution volume was $250 \mathrm{~mL}$. A $6 \mathrm{~W}$ Philips black light fluorescent lamp which basically emits at $350 \mathrm{~nm}$ was used as an artificial light source. The incident light intensity, measured with a uranyl actinometer, was $1.38 \times 10^{-9}$ Einstein $\mathrm{s}^{-1}$. A few Fenton reagent doses were tested in the present work (a series of three experiments): $5 \mathrm{mg} / \mathrm{L} \mathrm{Fe}(\mathrm{II})$ and $125 \mathrm{mg} / \mathrm{L}$ $\mathrm{H}_{2} \mathrm{O}_{2}, 10 \mathrm{mg} / \mathrm{L} \mathrm{Fe}(\mathrm{II})$ and $125 \mathrm{mg} / \mathrm{L} \mathrm{H}_{2} \mathrm{O}_{2}$ $10 \mathrm{mg} / \mathrm{L} \mathrm{Fe}(\mathrm{II})$ and $250 \mathrm{mg} / \mathrm{L} \mathrm{H}_{2} \mathrm{O}_{2}$. Contaminants with a ratio of $\mathrm{BOD} 5 / \mathrm{COD} \geq$ 0.4 are generally accepted as biodegradable, while those with ratios between 0.2 and 0.3 units were partially biodegradable.
The photo-Fenton degradation of SMX was strongly influenced by the seawater matrix when compared to distilled water. Indeed, in seawater it is proposed that degradation occurs mainly through $\mathrm{Cl}_{2}{ }^{1-}$ and $\mathrm{Cl}^{--}$(or $\mathrm{HO}_{2}{ }^{-}$) and not through $\mathrm{HO}^{-}$. The increased iron concentration showed a slight improvement on the pollutant degradation and mineralization rate. The increase of $\mathrm{H}_{2} \mathrm{O}_{2}$ concentration up to $120 \mathrm{mg} / \mathrm{L}$ in distilled water reduced the sample toxicity during the photo-Fenton process, which demonstrates that this is a feasible technology for the treatment of wastewater containing this compound.
Homo-bireactive dye (Procion Red H-E7 B)
The results demonstrated that a photo-Fenton reaction can be used successfully as a pretreatment process to biocompatibilize Procion Red H-E7B reactive dye solutions. The best pretreatment results were obtained with $60 \mathrm{~min}$ of photo-Fenton irradiation time and $10 \mathrm{mg} / \mathrm{L} \mathrm{Fe}$ (II) and $125 \mathrm{mg} / \mathrm{L} \mathrm{H}_{2} \mathrm{O}_{2}$ of initial reagent concentration. Under these conditions, the BOD5/COD index increased from 0.10 to 0.35 units with $39 \%$ mineralization and $16.5 \mathrm{mg} / \mathrm{L}$ of residual $\mathrm{H}_{2} \mathrm{O}_{2}$. The use of photo-Fenton type reactions as a pretreatment allows the SBR system to remove Procion Red H-E7B Reactive Dye from aqueous solution, which improves the low success rate of aerobic biological removal of dye colour. 
TABLE 4: Continued.

\begin{tabular}{|c|c|c|c|}
\hline Reference & Process conditions & Pollutant(s) & Conclusions \\
\hline$[56]$ & $\begin{array}{l}\text { This study explored the application of the } \\
\text { solar photoFenton process to the degradation } \\
\text { of PNA in water. The operating } \mathrm{pH} \text { value was } \\
\text { varied in the range of } 3-6 \text {. The effect, of } \mathrm{H}_{2} \mathrm{O}_{2} \\
\text { and } \mathrm{Fe}^{2+} \text { dosage on the degradation of PNA } \\
\text { by solar photo-Fenton process were } \\
\text { investigated between } 2.5-40 \text { and } \\
0.025-0.1 \mathrm{mM} \text {, respectively. Also the effect, of } \\
\text { temperature and initial pollutant } \\
\text { concentration were investigated in the range } \\
\text { of } 20-50^{\circ} \mathrm{C} \text { and } 72 \times 10^{-3}-217 \times 10^{-3} \mathrm{mM} \text {. }\end{array}$ & $\begin{array}{l}\text { P-Nitroaniline } \\
\text { (PNA) }\end{array}$ & $\begin{array}{l}\text { The optimum conditions for the degradation of } \\
\text { PNA in water were considered to be } \mathrm{pH} 3.0 \text {, } \\
10 \mathrm{mmol} / \mathrm{L} \mathrm{H}_{2} \mathrm{O}_{2}, 0.05 \mathrm{mmol} / \mathrm{L} \mathrm{Fe}^{2+} \text {, } \\
0.072-0.217 \mathrm{mmol} / \mathrm{L} \mathrm{PNA} \text {, and temperature } \\
20^{\circ} \mathrm{C} \text {. Under optimum conditions, the } \\
\text { degradation efficiencies of PNA were more than } \\
98 \% \text { within a } 30 \text { min reaction time. The } \\
\text { degradation characteristic of PNA showed that } \\
\text { the conjugated systems of the aromatic ring in } \\
\text { the PNA molecules were effectively destroyed. } \\
\text { The experimental results indicated that the solar } \\
\text { photo-Fenton process has advantages over the } \\
\text { classic Fenton process, such as higher oxidation } \\
\text { power, a wider working pH range, and a lower } \\
\text { ferrous ion usage. }\end{array}$ \\
\hline
\end{tabular}

During the experiment, $\mathrm{H}_{2} \mathrm{O}_{2}$ was added continuously to the reactor at a flow rate of $1 \mathrm{~mL} / \mathrm{min}$ with a syringe pump. Two $8 \mathrm{~W}$ monochromatic UV lamps of $312 \mathrm{~nm}$ (with an emission range between 280 and $360 \mathrm{~nm}$ ) were placed axially in the reactor and kept in place with a quartz sleeve. The UV intensity of [57] one $8 \mathrm{~W} \mathrm{UV} \mathrm{lamp} \mathrm{is} 60 \mu \mathrm{W} / \mathrm{cm}$. The reaction temperature was maintained at $25 \pm 1^{\circ} \mathrm{C}$ using a water bath. A two factor CCD was carried out using $\mathrm{H}_{2} \mathrm{O}_{2}$ dosage rate ranging from 1 to $10 \mathrm{mg} / \mathrm{L} \mathrm{min}$ and $\mathrm{Fe}^{3+}$ dosage from 1 to $100 \mathrm{mg} / \mathrm{L}$ to investigate their influence on carbofuran degradation under the photo-Fenton process.

Experiments were carried out in a Pyrex glass cylindrical reactor of $0.10 \mathrm{~m}$ diameter and $0.20 \mathrm{~m}$ height. The working volume was $1 \mathrm{~L}$ and all experiments were conducted in batch mode. The initial solution $\mathrm{pH}$ was adjusted to 3 which is the optimal value for the Fenton and photo-Fenton reactions using sulphuric [58] acid. All experiments except those in the dark and at night were carried out between $10 \mathrm{am}$ and $4 \mathrm{pm}$. The mean solar radiation during the experiments from October to January was in the range of $2.55-3.01 \mathrm{kWh}\left(\mathrm{m}^{2} \text { day }\right)^{-1}$. The effects of solar light, initial Fe concentration, and initial $\mathrm{H}_{2} \mathrm{O}_{2}$ concentration were investigated.
Under these conditions, the toxicity unit measured by Microtox test with 5 min exposure was decreased from 47 to 6 and the biodegradability evaluated by BOD 5/COD ratio was increased from 0 to 0.76 after a $60 \mathrm{~min}$ reaction. The results obtained in this study demonstrate that the photo-Fenton process is a promising pretreatment to biological treatment for carbofuran removal from contaminated water or wastewater.
Acid Orange 7
With increasing Fe dosage the decolourization rate increased, but the enhancement was not pronounced beyond $10 \mathrm{mg} / \mathrm{L}$. Although the addition of $\mathrm{H}_{2} \mathrm{O}_{2}$ increased the decolourization rate up to around $1000 \mathrm{mg} / \mathrm{L}$ of $\mathrm{H}_{2} \mathrm{O}_{2}$, further additions of $\mathrm{H}_{2} \mathrm{O}_{2}$ did not enhance colour removal. At excess dosages of Fenton reagents, colour removal was not improved, due to their scavenging of hydroxyl radicals. It was found that the pseudo first-order decolourization kinetic constant based on the accumulated solar energy is the sole parameter unifying solar photo-Fenton decolourization processes under different weather conditions.
The oxidation power of the photo-Fenton process is attributed to the generation of $\mathrm{OH}$ radicals. Without irradiation, a Fenton-like reaction occurred instead of a photoFenton reaction. The Fenton-like reaction is a reaction of $\mathrm{Fe}^{3+}$ with $\mathrm{H}_{2} \mathrm{O}_{2}$, which causes the reduction of $\mathrm{Fe}^{3+}$ to $\mathrm{Fe}^{2+}$ :

$$
\mathrm{Fe}^{3+}+\mathrm{H}_{2} \mathrm{O}_{2} \longrightarrow \mathrm{Fe}^{2+}+{ }^{\circ} \mathrm{OOH}+\mathrm{H}^{+}
$$

Since Reaction (30) occurs instead of Reaction (27), organic pollutants are mineralized even without irradiation. It should be noted, however, that Reaction (30) is rather slower than Reaction (27). Thus the degradation rate under dark conditions is rather lower than that of the photoFenton reaction [136]. Figure 3 shows the reaction pathways for the process starting with the primary photoreduction of the dissolved $\mathrm{Fe}$ (III) complexes to $\mathrm{Fe}(\mathrm{II})$ ions followed by Fenton's reaction and the subsequent oxidation of organic compounds. Additional hydroxyl radicals generated in the first step also take part in the oxidation reaction [140].

Appropriate implementation of the photo-Fenton treatment depends mainly on the operating variables$\mathrm{H}_{2} \mathrm{O}_{2} / \mathrm{COD}$ molar ratio, $\mathrm{H}_{2} \mathrm{O}_{2} / \mathrm{Fe}^{2+}$ molar ratio, and irradiation time. The conventional method is to optimize 


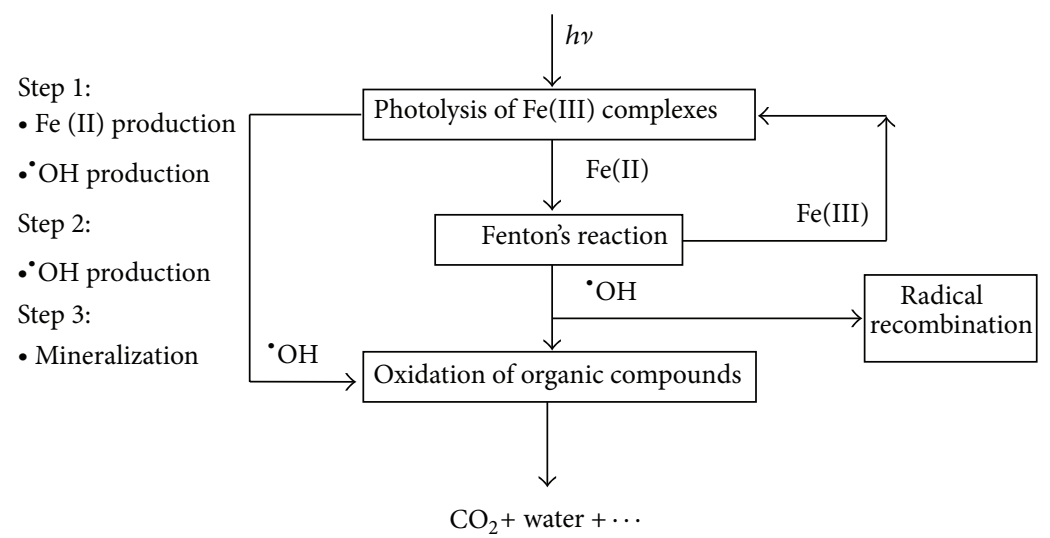

FIgURE 3: Reaction pathways of the photo-Fenton process.

the operating variables by changing one factor at a time; that is, a single factor is varied while all other factors are kept unchanged for a particular set of experiments. Likewise, other variables are individually optimized through single-dimensional searches, which are time consuming and incapable of reaching the actual optimum as interaction among variables is not taken into consideration [141]. Some illustrative works from recent years are discussed in detail in Table 4 .

\section{4. $\mathrm{UV} / \mathrm{H}_{2} \mathrm{O}_{2}$ Process}

Like other AOPs, the oxidizing ability of $\mathrm{UV} / \mathrm{H}_{2} \mathrm{O}_{2}$ may be attributed to the formation of ${ }^{\bullet} \mathrm{OH}, \mathrm{HO}_{2}{ }^{\bullet}$, and $\mathrm{O}_{2}{ }^{-\bullet}$ as reflected by their mechanistic pathways (Reactions (1), (19)(23)). In fact, the AOP occurs via a reaction with ${ }^{\circ} \mathrm{OH}$ radicals, produced by UV irradiation of $\mathrm{H}_{2} \mathrm{O}_{2}$. The molar absorptivity of hydrogen peroxide is low at $253.7 \mathrm{~nm}$, about $20 \mathrm{M}^{-1} \mathrm{~cm}^{-1}$, and $\cdot \mathrm{OH}$ radicals are formed per incident photon absorbed [104]. At this wavelength, the photolysis rate of aqueous hydrogen peroxide is about 50 times slower than that of ozone [104]. This technique requires a relatively high dose of $\mathrm{H}_{2} \mathrm{O}_{2}$ and/or a much longer UV exposure time than, for example, the $\mathrm{UV} / \mathrm{O}_{3}$ process. In contrast, the rate of photolysis of hydrogen peroxide has been found to be $\mathrm{pH}$ dependent and increases when more alkaline conditions are used, because at $253.7 \mathrm{~nm}$ peroxide anions $\mathrm{HO}_{2}{ }^{-}$may be formed, which display a higher molar absorptivity than hydrogen peroxide, namely, $240 \mathrm{M}^{-1} \mathrm{~cm}^{-1}[104,142]$. In this AOP, the formation of ${ }^{\bullet} \mathrm{OH}$ radicals is directly facilitated by the photolysis of $\mathrm{H}_{2} \mathrm{O}_{2}$ [143]. The radicals, which are formed by the homolytic splitting of the oxidant's $\mathrm{O}-\mathrm{O}$ bonds, transform the chemical structures of target chelating agents $[143,144]$. Consider the following:
Initiation (Rate Constant)

$$
\begin{array}{r}
\mathrm{H}_{2} \mathrm{O}_{2}+h v \longrightarrow 2^{\bullet} \mathrm{OH}\left(k=5: 3 \times 10^{9} \mathrm{M}^{-1} \mathrm{~s}^{-1}\right) \\
\mathrm{H}_{2} \mathrm{O}_{2} \rightleftharpoons \mathrm{HO}_{2}^{-}+\mathrm{H}^{+} \quad \mathrm{pKa}=11: 62 \\
\left(k=1: 25 \times 10^{-2} \mathrm{~s}^{-1}\right)
\end{array}
$$

Propagation [144] (Rate Constant)

$$
\begin{gathered}
\cdot \mathrm{OH}+\mathrm{H}_{2} \mathrm{O}_{2} \longrightarrow \mathrm{HO}_{2}^{\cdot}+\mathrm{H}_{2} \mathrm{O} \\
\left(k=2: 7 \times 10^{7} \mathrm{M}^{-1} \mathrm{~s}^{-1}\right) \\
\mathrm{H}_{2} \mathrm{O}_{2}+\mathrm{O}_{2}^{-\bullet} \longrightarrow \mathrm{O}_{2}+\mathrm{OH}^{-} \\
\left(k=0.5 \mathrm{M}^{-1} \mathrm{~s}^{-1}\right) \\
\mathrm{HO}_{2}{ }^{-}+\mathrm{O}_{2} \longrightarrow \mathrm{HO}_{2}{ }^{-}+\mathrm{O}_{2}^{-\bullet}
\end{gathered}
$$

Termination [144] (Rate Constant)

$$
\begin{gathered}
{ }^{\circ} \mathrm{OH}+\mathrm{HO}_{2}{ }^{-} \longrightarrow \mathrm{H}_{2} \mathrm{O}+\mathrm{O}_{2} \quad \mathrm{pH}=3 \\
\left(k=7.15 \times 10^{9} \mathrm{M}^{-1} \mathrm{~s}^{-1}\right) \\
{ }^{\circ} \mathrm{OH}+{ }^{\circ} \mathrm{OH} \longrightarrow \mathrm{H}_{2} \mathrm{O}_{2} \\
\left(k=5.2 \times 10^{9} \mathrm{M}^{-1} \mathrm{~s}^{-1}\right)
\end{gathered}
$$

It is important to note that the effectiveness of $\mathrm{UV} / \mathrm{H}_{2} \mathrm{O}_{2}$ systems depends on various conditions that affect their ability to degrade chelating agents. The variables include the type and concentration of contaminants or dissolved inorganic substances (such as carbonates and iron cations), organic substances present in surface water, light transmittance in 
TABLE 5: Typical findings observed in work related to the use of $\mathrm{UV} / \mathrm{H}_{2} \mathrm{O}_{2}$.

\begin{tabular}{|c|c|c|c|}
\hline Reference & Process conditions & Pollutant(s) & Conclusions \\
\hline [59] & $\begin{array}{l}\text { For photolytic experiments, the samples } \\
\text { were irradiated with a UV lamp with an } \\
\text { output of } 254 \mathrm{~nm} \text { operating at } 50-60 \mathrm{~Hz} \\
\text { with a current intensity of } 0.12 \mathrm{~A} \text { at } \\
\text { ambient temperature. The photolytic } \\
\text { decolouration of carmine via UV } \\
\text { radiation in the presence of } \mathrm{H}_{2} \mathrm{O}_{2} \text { was } \\
\text { optimized using response surface } \\
\text { methodology (RSM) utilizing } \\
\text { Design-Expert 7.1. }\end{array}$ & $\begin{array}{c}\text { Carmine } \\
\text { (C.I. Natural Red 4) }\end{array}$ & $\begin{array}{l}\text { Under the optimized conditions of } \\
62 \mu \mathrm{M} \text { dye, } 5.5 \mathrm{mM} \mathrm{H}_{2} \mathrm{O}_{2} \text {, and } \mathrm{pH} 4 \text {, the } \\
\text { experimental values were as predicted, } \\
\text { indicating the suitability of the model and } \\
\text { the success of RSM in optimizing } \\
\text { photooxidation conditions for carmine } \\
\text { dye. In the optimization, } R^{2} \text { and } R^{2} \text { adj } \\
\text { correlation coefficients for the quadratic } \\
\text { model were evaluated quite satisfactorily } \\
\text { at } 0.998 \text { and } 0.997 \text {, respectively. }\end{array}$ \\
\hline
\end{tabular}

$\mathrm{UV} / \mathrm{TiO}_{2} / \mathrm{H}_{2} \mathrm{O}_{2}, \mathrm{UV} / \mathrm{TiO}_{2}$, and

$\mathrm{UV} / \mathrm{H}_{2} \mathrm{O}_{2}$ were compared as pretreatment processes to detoxification and treatment. The tubes were then

[60] irradiated for $40 \mathrm{~h}$ (initial concentrations of $50 \mathrm{mg} / \mathrm{L}$ ) or $56 \mathrm{~h}$ (initial concentrations of $100 \mathrm{mg} / \mathrm{L}$ ) at $300 \mu \mathrm{W} \mathrm{cm} \mathrm{cm}^{-2}$ with two $18 \mathrm{~W}$ UV bluelamps and an initial chlorophenol concentration of $50 \mathrm{mg} / \mathrm{L}$.

A $60 \mathrm{~W}$ mercury vapour lamp (UV C, $253.7 \mathrm{~nm}$ ) with a frequency of $50 \mathrm{~Hz}$ and a voltage of $240 \mathrm{~V}$ was used. The initial concentrations of $\mathrm{H}_{2} \mathrm{O}_{2}$ and melanoidin were manipulated while $\mathrm{pH}$, flow rate,

[61] irradiated surface area, volume, lamp intensity, and temperature were kept constant. The relative change of each constituent was identified at various initial concentrations of $\mathrm{H}_{2} \mathrm{O}_{2}$ (up to $12000 \mathrm{mg} / \mathrm{L}$ ) and melanoidin (263-5314 mg-Pt Co/L).

4-Chlorophenol (4CP), 2,4-dichlorophenol (DCP),

2,4,6-trichlorophenol (TCP), and pentachlorophenol (PCP)
Chlorophenol photodegradation was well described by a first-order model kinetic $\left(r^{2}>0.94\right)$ and the shortest 4CP, DCP, TCP, and PCP half-lives were achieved during $\mathrm{UV} / \mathrm{TiO}_{2} / \mathrm{H}_{2} \mathrm{O}_{2}$ treatment at 8.7, $7.1,4.5$, and $3.3 \mathrm{~h}$, respectively.
This study compared the efficacy of UV photodegradation with that of different advanced oxidation processes $\left(\mathrm{O}_{3}\right.$, $\mathrm{UV} / \mathrm{H}_{2} \mathrm{O}_{2}, \mathrm{O}_{3}$ /activated carbon). Photo-irradiations were carried out using a merry-go-round photoreactor (MGRR), DEMA equipped with a 500 WTQ 718 Heraeus medium-pressure mercury lamp (239-334 nm) or a TNN 15/32 Heraeus low-pressure mercury lamp $(254 \mathrm{~nm})$. The temperature in the MGRR was kept at $25.0 \pm 0.2^{\circ} \mathrm{C}$ during all irradiations. The concentration of $\mathrm{H}_{2} \mathrm{O}_{2}$ used was $3 \mathrm{mM}$.

The reactor had a $1 \mathrm{~L}$ capacity and was equipped with a mercury medium-pressure steam UV lamp which was $110 \mathrm{~mm}$ in length and used $1000 \mathrm{~W}$, $145 \mathrm{~V}$, and $7.5 \mathrm{~A}$. In the UV light $/ \mathrm{H}_{2} \mathrm{O}_{2}$ flow reactor system, the initial [63] concentration of sulphide was $6.34 \mathrm{mg} \mathrm{L}^{-1}$. The initial concentrations of sulphurous water were $6.34 \mathrm{mg} \mathrm{L}^{-1}$ of $\mathrm{HS}^{-}, 1000 \mathrm{mg} \mathrm{L}^{-1}$ of $\mathrm{SO}_{4}{ }^{2-}$, and $1.5 \mathrm{mg} \mathrm{L}^{-1}$ of $\mathrm{SO}_{4}{ }^{2-}$. The amount of hydrogen peroxide added was of $6 \times 10^{-4} \mathrm{~mL} \mathrm{~L}^{-1}$
$\mathrm{UV} / \mathrm{H}_{2} \mathrm{O}_{2}$ was shown to remove the colour associated with melanoidin effectively. The process was less effective in removing the DON and DOC present in the melanoidin solution. At the optimum $\mathrm{H}_{2} \mathrm{O}_{2}$ dose $(3300 \mathrm{mg} / \mathrm{L})$, with an initial melanoidin concentration of $2000 \mathrm{mg} / \mathrm{L}$, the removal of colour, DOC and DON was $99 \%, 50 \%$, and $25 \%$, respectively.

These results demonstrated that the treatment of naphthalene sulphonic acids with UV radiation is not effective in their removal from aqueous solutions. The presence of duroquinone and 4-carboxybenzophenone during the irradiation of naphthalene sulphonic acids increases their elimination rate. $\mathrm{O}_{3}$ /activated carbon and $\mathrm{UV} / \mathrm{H}_{2} \mathrm{O}_{2}$ based systems were found to be more efficient than the irradiation process in the removal of naphthalene sulphonic acids from aqueous solutions.
Naphthalene sulphonic acids

Sulphurous water
In a batch reactor it was possible to demonstrate that the sulphur compounds of the sulphurous waters could be oxidized to sulphate in a UV light $/ \mathrm{H}_{2} \mathrm{O}_{2}$ air system with very small concentrations of hydrogen peroxide $\left(6 \times 10^{-3} \mathrm{~mL} \mathrm{~L}^{-1}\right)$. In a flow reactor it was possible to obtain the same results by adding only $6 \times 10^{-4} \mathrm{~mL} \mathrm{~L}^{-1}$ of hydrogen peroxide. 
TABLE 5: Continued.

\begin{tabular}{|c|c|c|c|}
\hline Reference & Process conditions & Pollutant(s) & Conclusions \\
\hline$[64]$ & $\begin{array}{l}\text { Radiation energy was supplied by two } \\
\text { lamps. Two different types of lamp were } \\
\text { used: (1) two Philips TUV lamps with an } \\
\text { input power of } 15 \mathrm{~W} \text { each and (2) two } \\
\text { Heraeus UV-C lamps operated with an } \\
\text { input power of } 40 \mathrm{~W} \text { each. Both types of } \\
\text { lamp are low pressure mercury vapour } \\
\text { lamps with one single significant } \\
\text { emission wavelength at } 253.7 \mathrm{~nm} \text {. DCA } \\
\text { concentration and radiation absorbing } \\
\text { species concentration }\left(\mathrm{H}_{2} \mathrm{O}_{2}\right) \text { were } \\
60 \text { ppm, } 145 \text { ppm and pH and } \\
\text { temperature were kept at } 3.4 \text { and } 20^{\circ} \mathrm{C} \text {, } \\
\text { respectively. }\end{array}$ & $\begin{array}{l}\text { Dichloroacetic acid } \\
\text { (DCA) }\end{array}$ & $\begin{array}{l}\text { The fastest degradation rate was obtained } \\
\text { with the } \mathrm{H}_{2} \mathrm{O}_{2} / \mathrm{UV}^{40 \mathrm{~W}} \text { system, followed } \\
\text { by } \mathrm{H}_{2} \mathrm{O}_{2} / \mathrm{UV}^{15 \mathrm{~W}} \text {. Although the } \\
\text { photocatalytic process was effective in } \\
\text { degrading DCA, the reaction rate was } \\
\text { much slower when compared with the } \\
\text { homogeneous processes. For the } \\
\mathrm{H}_{2} \mathrm{O}_{2} / \mathrm{UV}^{40 \mathrm{~W}} \text { reaction, the DCA } \\
\text { conversion at } t_{\text {eff }}=530 \mathrm{~s} \text { (ca. } 4 \mathrm{~h} \text { of } \\
\text { reaction) is more than } 80 \% \text {, whereas the } \\
\mathrm{H}_{2} \mathrm{O}_{2} / \mathrm{UV}^{15 \mathrm{~W}} \text { system reaches half of this } \\
\text { value. The DCA and TOC conversion } \\
\text { values are similar in each process. This is } \\
\text { in agreement with the fact that there are } \\
\text { no stable reaction intermediates and } \\
\text { DCA is rapidly converted into } \mathrm{HCl} \text { and } \\
\mathrm{CO}_{2} \text {. }\end{array}$ \\
\hline$[65]$ & $\begin{array}{l}\text { Low pressure mercury vapour lamps with } \\
\text { a maximum emission primarily at } \\
253.7 \mathrm{~nm} \text { were used as the light source. } \\
\text { The changes in the } \mathrm{pH} \text { of dye solutions as } \\
\text { a function of the irradiation time for } \\
\text { different initial } \mathrm{pH} \text { values are carried out. } \\
\text { The effect of the initial } \mathrm{H}_{2} \mathrm{O}_{2} \\
\text { concentration in a range of } 10-100 \mathrm{mM} \\
\text { on the rate of RO16 decolourization was } \\
\text { investigated. The effect of the initial RO16 } \\
\text { concentration in a range from } 20 \text { to } \\
80 \text { mg dm }{ }^{-3} \text { on the efficiency of dye } \\
\text { degradation was also investigated. The } \\
\text { influence of UV light intensity on the } \\
\text { decolourization of RO16 azo dye was } \\
\text { monitored by varying the light intensity } \\
\text { from } 730 \text { up to } 1950 \mu \mathrm{W} \mathrm{cm}^{-2} \text {. }\end{array}$ & $\begin{array}{c}\text { Azo dye Reactive } \\
\text { Orange } 16\end{array}$ & $\begin{array}{l}\text { The UV/ } \mathrm{H}_{2} \mathrm{O}_{2} \text { process could be used } \\
\text { efficiently for the decolourization of } \\
\text { aqueous solutions of the azo dye Reactive } \\
\text { Orange } 16 \text {. It was found that the rate of } \\
\text { decolourization is significantly affected } \\
\text { by the initial pH, the initial hydrogen } \\
\text { peroxide concentration, the initial dye } \\
\text { concentration, and the UV light intensity. } \\
\text { The decolourization follows pseudo } \\
\text { first-order reaction kinetics. Peroxide } \\
\text { concentrations in the range from } 20 \text { to } \\
40 \text { mM appear to be optimal. Colour } \\
\text { removal was observed to be faster in } \\
\text { neutral pH solutions than in acidic and } \\
\text { basic ones. The hydroxyl radical } \\
\text { scavenging effect of the examined } \\
\text { inorganic anions increased in the order } \\
\text { phosphate }<\text { sulphate }<\text { nitrate }<\text { chloride. }\end{array}$ \\
\hline
\end{tabular}

solutions (as indicated by turbidity or colour), $\mathrm{pH}$, temperature, and the optimum oxidant dose [145]. An excessive concentration of $\mathrm{H}_{2} \mathrm{O}_{2}$ would act as a radical scavenger, slowing down the rate of oxidation [146], while a low concentration of $\mathrm{H}_{2} \mathrm{O}_{2}$ insufficiently forms $\mathrm{OH}$ radicals in aqueous solutions, leading to a slower oxidation rate $[143,147]$. The $\mathrm{UV} / \mathrm{H}_{2} \mathrm{O}_{2}$ process is sensitive to the scavenging effects of carbonate ions at a $\mathrm{pH}$ ranging from 8 to 9. Furthermore, the $\mathrm{UV} / \mathrm{H}_{2} \mathrm{O}_{2}$ process requires a long UV exposure time with a powerful output at a wide range of wavelengths. Nevertheless this treatment is more economically attractive than the $\mathrm{UV} / \mathrm{O}_{3}$ process, due to its lower energy consumption [143, 148].

Tubular reactor configurations are usually employed for direct photolysis and photo-Fenton processes or processes based on $\mathrm{H}_{2} \mathrm{O}_{2} / \mathrm{UV}$ reagent, in order to achieve a good interaction between CPs, other intermediates, and radiation $[104,149]$. Also various lamps are employed to generate the radiation supplied to $\mathrm{CP}$ samples for direct UV photolysis and for techniques based on $\mathrm{UV} / \mathrm{H}_{2} \mathrm{O}_{2}, \mathrm{UV} / \mathrm{O}_{3}$, photoFenton processes, and photocatalysis. The various commercial radiation sources employed include high, medium, and low pressure mercury vapour lamps for the generation of UV radiation [149-151] and solar-simulated xenon lamps as a source of visible radiation [152]. The lamp can be located either in an axial position housed by a sleeve [150] or vertically, in its centre [104]. The typical findings observed in the $\mathrm{UV} / \mathrm{H}_{2} \mathrm{O}_{2}$ process are listed in Table 5.

Ultimate oxidation of CPs to carbon dioxide and water has rarely been obtained under typical test conditions. As summarized in Table 4, typical half-life times are between 0.3 and 20.1 minutes for CP degradation, depending on the initial concentration of $\mathrm{CP}$ and hydrogen peroxide, the intensity of radiation, and the degree of chlorination. It is observed that the degradation rates increase when the number of chlorine substituents decreases [104].

\section{Conclusion}

Recent developments in various homogeneous AOPs have been analysed comprehensively. The principle of individual 
and combined AOPs and their efficiency on the degradation of various pollutants was discussed. The influence of various experimental parameters such as oxidant dosage, solution $\mathrm{pH}$, flow rates, substrate concentrations, water matrix, and light intensity on the AOPs was explored. This review also listed various AOPs applied for the degradation of contaminants under different experimental conditions. Combined AOPs substantially enhanced the degradation rate by generating more reactive radicals under suitable conditions. The optimum oxidant dosage and solution for efficient removal were reported.

\section{Conflict of Interests}

The authors declare that there is no conflict of interests regarding the publication of this paper.

\section{Acknowledgments}

The authors wish to thank the National Science Council (NSC) in Taiwan for their financial support under the Contract no. NSC-101-2221-035-031-MY3. The Laboratory of Green Chemistry, Mikkeli, Finland, and Water and Environmental Technology (WET) Center, Temple University, are also gratefully acknowledged for their partial financial support of this study.

\section{References}

[1] http://www.unesco.org/water/news/newsletter/184.shtml.

[2] http://www.un.org/News/Press/docs/2010/ga10967.doc.htm.

[3] http://www.who.int/water_sanitation_health/recognition_safe_ clean_water/en/index.html.

[4] H. Kim, J. Shim, and S. Lee, "Formation of disinfection byproducts in chlorinated swimming pool water," Chemosphere, vol. 46, no. 1, pp. 123-130, 2002.

[5] G. C. White, Handbook of Chlorination and Alternative Disinfectants, Van Nostrand Reinhold, New York, NY, USA, 3rd edition, 1992.

[6] Z. Aksu and J. Yener, "A comparative adsorption/biosorption study of mono-chlorinated phenols onto various sorbents," Waste Management, vol. 21, no. 8, pp. 695-702, 2001.

[7] S. C. J. M. Van Hoof, A. Hashim, and A. J. Kordes, "The effect of ultrafiltration as pretreatment to reverse osmosis in wastewater reuse and seawater desalination applications," Desalination, vol. 124, no. 1-3, pp. 231-242, 1999.

[8] D. Keenan and A. Sabelnikov, "Biological augmentation eliminates grease and oil in bakery wastewater," Water Environment Research, vol. 72, no. 2, pp. 141-146, 2000.

[9] G. Chen, X. Chen, and P. L. Yue, "Electrocoagulation and electroflotation of restaurant wastewater," Journal of Environmental Engineering, vol. 126, no. 9, pp. 858-863, 2000.

[10] M. J. Dietrich, T. L. Randall, and P. J. Canney, "Wet air oxidation of hazardous organics in wastewater," Environmental Progress, vol. 4, no. 3, pp. 171-177, 1985.

[11] M. Muruganandham and M. Swaminathan, "Advanced oxidative decolourisation of reactive yellow 14 azo dye by $\mathrm{UV} / \mathrm{TiO}_{2}$, $\mathrm{UV} / \mathrm{H}_{2} \mathrm{O}_{2}, \mathrm{UV} / \mathrm{H}_{2} \mathrm{O}_{2} / \mathrm{Fe}^{2+}$ processes-a comparative study," Separation \& Purification Technology, vol. 48, no. 3, pp. 297-303, 2006.
[12] M. Paleia, G. Ifrim, M. Barbu, G. Bahrim, and S. Caraman, "Strategies for the aerobic biological treatment of the dairy wastewaters in controlled conditions," Environmental Engineering \& Management Journal, vol. 9, no. 3, pp. 399-405, 2010.

[13] M. Muruganandham, S. H. Chen, and J. J. Wu, "Mineralization of N-methyl-2-pyrolidone by advanced oxidation processes," Separation \& Purification Technology, vol. 55, no. 3, pp. 360-367, 2007.

[14] J. J. Wu, M. Muruganandham, L. T. Chang, G. J. Lee, V. N. Batalova, and G. M. Mokrousov, "Catalytic ozonation of oxalic acid using $\mathrm{SrTiO}_{3}$ catalyst," Ozone: Science \& Engineering, vol. 33, no. 1, pp. 74-79, 2011.

[15] J. J. Wu, S. H. Chen, and M. Muruganandham, "Catalytic ozonation of oxalic acid using carbon-free rice husk ash catalysts," Industrial \& Engineering Chemistry Research, vol. 47, no. 9, pp. 2919-2925, 2008.

[16] S. Vilhunen, M. Vilve, M. Vepsäläinen, and M. Sillanpää, "Removal of organic matter from a variety of water matrices by UV photolysis and UV/ $\mathrm{H}_{2} \mathrm{O}_{2}$ method," Journal of Hazardous Materials, vol. 179, no. 1-3, pp. 776-782, 2010.

[17] M. Muruganandham and M. Swaminathan, "Decolourisation of reactive orange 4 by Fenton and photo-Fenton oxidation technology," Dyes \& Pigments, vol. 63, no. 3, pp. 315-321, 2004.

[18] A. Matilainena and M. Sillanpää, "Removal of natural organic matter from drinking water by advanced oxidation processes," Chemosphere, vol. 80, no. 4, pp. 351-365, 2011.

[19] J. J. Wu, J. S. Yang, M. Muruganandham, and C. C. Wu, “The oxidation study of 2-propanol using ozone-based advanced oxidation processes," Separation \& Purification Technology, vol. 62, no. 1, pp. 39-46, 2008.

[20] N. N. Mahamuni and Y. G. Adewuyi, "Advanced oxidation processes (AOPs) involving ultrasound for wastewater treatment: a review with emphasis on cost estimation," Ultrasonics Sonochemistry, vol. 17, no. 6, pp. 990-1003, 2010.

[21] M. Muruganandham, J.-S. Yang, and J. J. Wu, "Effect of ultrasonic irradiation on the catalytic activity and stability of goethite catalyst in the presence of $\mathrm{H}_{2} \mathrm{O}_{2}$ at acidic medium," Industrial \& Engineering Chemistry Research, vol. 46, no. 3, pp. 691-698, 2007.

[22] M. Muruganandham, R. Amutha, G.-J. Lee, S.-H. Hsieh, J. J. $\mathrm{Wu}$, and M. Sillanpaa, "Facile fabrication of tunable $\mathrm{Bi}_{2} \mathrm{O}_{3}$ selfassembly and its visible light photocatalytic activity," Journal of Physical Chemistry C, vol. 116, no. 23, pp. 12906-12915, 2012.

[23] M. Muruganandham, R. Amutha, E. Repo, M. Sillanpää, Y. Kusumoto, and M. Abdulla-Al-Mamun, "Controlled mesoporous self-assembly of $\mathrm{ZnS}$ microsphere for photocatalytic degradation of Methyl Orange dye," Journal of Photochemistry and Photobiology A, vol. 216, no. 2-4, pp. 133-141, 2010.

[24] T. Garoma and M. D. Gurol, "Degradation of tert-butyl alcohol in dilute aqueous solution by an $\mathrm{O}_{3} / \mathrm{UV}$ process," Environmental Science \& Technology, vol. 38, no. 19, pp. 5246-5252, 2004.

[25] N. A. Medellin-Castillo, R. Ocampo-Perez, R. Leyva-Ramos, M. Sanchez-Polo, J. Rivera-Utrilla, and J. D. Mendez-Diaz, "Removal of diethyl phthalate from water solution by adsorption, photo-oxidation, ozonation and advanced oxidation process (UV/ $\mathrm{H}_{2} \mathrm{O}_{2}, \mathrm{O}_{3} / \mathrm{H}_{2} \mathrm{O}_{2}$ and $\mathrm{O}_{3}$ /activated carbon)," Science of the Total Environment, vol. 442, pp. 26-35, 2013.

[26] S. C. Kwon, J. Y. Kim, S. M. Yoon, W. Bae, K. S. Kang, and Y. W. Rhee, "Treatment characteristic of 1,4-dioxane by ozonebased advanced oxidation processes," Journal of Industrial \& Engineering Chemistry, vol. 18, no. 6, pp. 1951-1955. 
[27] H. Kusic, N. Koprivanac, and A. L. Bozic, "Minimization of organic pollutant content in aqueous solution by means of AOPs: UV- and ozone-based technologies," Chemical Engineering Journal, vol. 123, no. 3, pp. 127-137, 2006.

[28] X. Jin, S. Peldszus, and P. M. Huck, "Reaction kinetics of selected micropollutants in ozonation and advanced oxidation processes," Water Research, vol. 46, no. 19, pp. 6519-6530, 2012.

[29] F. J. Rivas, M. Carbajo, F. Beltrán, O. Gimeno, and J. Frades, "Comparison of different advanced oxidation processes (AOPs) in the presence of perovskites," Journal of Hazardous Materials, vol. 155, no. 3, pp. 407-414, 2008.

[30] I. Peternel, N. Koprivanac, and I. Grcic, "Mineralization of p-chlorophenol in water solution by AOPs based on UV irradiation," Environmental Technology, vol. 33, no. 1, pp. 27-36, 2012.

[31] A. K. Biń, P. Machniewski, R. Sakowicz, J. Ostrowska, and J. Zieliński, "Degradation of nitroaromatics (MNT, DNT and TNT) by AOPs," Ozone: Science \& Engineering, vol. 23, no. 5, pp. 343-349, 2001.

[32] K. Wang, J. Guo, M. Yang, H. Junji, and R. Deng, "Decomposition of two haloacetic acids in water using UV radiation, ozone and advanced oxidation processes," Journal of Hazardous Materials, vol. 162, no. 2-3, pp. 1243-1248, 2009.

[33] M. Y. Ghaly, G. Härtel, R. Mayer, and R. Haseneder, "Aromatic compounds degradation in water by using ozone and AOPS. A comparative study. O-Nitrotoluene as a model substrate," Ozone: Science \& Engineering, vol. 23, no. 2, pp. 127-138, 2001.

[34] O. Gimeno, M. Carbajo, F. J. Beltrán, and F. J. Rivas, "Phenol and substituted phenols AOPs remediation," Journal of Hazardous Materials, vol. 119, no. 1-3, pp. 99-108, 2005.

[35] J. B. Parsa and S. H. Negahdar, "Treatment of wastewater containing acid blue 92 dye by advanced ozone-based oxidation methods," Separation \& Purification Technology, vol. 98, no. 19, pp. 315-320, 2012.

[36] J. Rivera-Utrilla, J. Méndez-Díaz, M. Sánchez-Polo, M. A. FerroGarcía, and I. Bautista-Toledo, "Removal of the surfactant sodium Dodecylbenzenesulfonate from water by simultaneous use of ozone and powdered activated carbon: comparison with systems based on $\mathrm{O}_{3}$ and $\mathrm{O}_{3} / \mathrm{H}_{2} \mathrm{O}_{2}$," Water Research, vol. 40, no. 8, pp. 1717-1725, 2006.

[37] I. Arslan, I. A. Balcioglu, and T. Tuhkanen, "Advanced oxidation of synthetic dyehouse effluent by $\mathrm{O}_{3}, \mathrm{H}_{2} \mathrm{O}_{2} / \mathrm{O}_{3}$ and $\mathrm{H}_{2} \mathrm{O}_{2} / \mathrm{UV}$ processes," Environmental Technology, vol. 20, no. 9, pp. 921-931, 1999.

[38] R. Kidak and N. H. Ince, "Catalysis of advanced oxidation reactions by ultrasound: a case study with phenol," Journal of Hazardous Materials, vol. 146, no. 3, pp. 630-635, 2007.

[39] G. Tezcanli-Güyer and N. H. Ince, "Individual and combined effects of ultrasound, ozone and UV irradiation: a case study with textile dyes," Ultrasonics, vol. 42, no. 1-9, pp. 603-609, 2004.

[40] I. A. Alaton and S. Teksoy, "Acid dyebath effluent pretreatment using Fenton's reagent: process optimization, reaction kinetics and effects on acute toxicity," Dyes \& Pigments, vol. 73, no. 1, pp. 31-39, 2007.

[41] H. Kušić, A. Lončarić Božić, and N. Koprivanac, "Fenton type processes for minimization of organic content in coloured wastewaters: part I: processes optimization," Dyes \& Pigments, vol. 74, no. 2, pp. 380-387, 2007.

[42] K. Pirkanniemi, S. Metsärinne, and M. Sillanpää, "Degradation of EDTA and novel complexing agents in pulp and paper mill process and wastewaters by Fenton's reagent," Journal of Hazardous Materials, vol. 147, no. 1-2, pp. 556-561, 2007.

[43] M. A. Behnajady, N. Modirshahla, and F. Ghanbary, "A kinetic model for the decolorization of C.I. Acid Yellow 23 by Fenton process," Journal of Hazardous Materials, vol. 148, no. 1-2, pp. 98-102, 2007.

[44] S.-P. Sun, C.-J. Li, J.-H. Sun, S.-H. Shi, M.-H. Fan, and Q. Zhou, "Decolorization of an azo dye Orange $G$ in aqueous solution by Fenton oxidation process: effect of system parameters and kinetic study," Journal of Hazardous Materials, vol. 161, no. 2-3, pp. 1052-1057, 2009.

[45] C. S. D. Rodrigues, L. M. Madeira, and R. A. R. Boaventura, "Optimization of the azo dye Procion Red H-EXL degradation by Fenton's reagent using experimental design," Journal of Hazardous Materials, vol. 164, no. 2-3, pp. 987-994, 2009.

[46] E. C. Catalkaya and F. Kargi, "Advanced oxidation and mineralization of simazine using Fenton's reagent," Journal of Hazardous Materials, vol. 168, no. 2-3, pp. 688-694, 2009.

[47] K. Ayoub, S. Nélieu, E. D. Van Hullebusch, A. Maia-Grondard, M. Cassir, and A. Bermond, "TNT oxidation by Fenton reaction: reagent ratio effect on kinetics and early stage degradation pathways," Chemical Engineering Journal, vol. 173, no. 2, pp. 309-317, 2011.

[48] J.-H. Sun, S.-P. Sun, G.-L. Wang, and L.-P. Qiao, "Degradation of azo dye Amido black 10B in aqueous solution by Fenton oxidation process," Dyes \& Pigments, vol. 74, no. 3, pp. 647-652, 2007.

[49] A. A. Burbano, D. D. Dionysiou, M. T. Suidan, and T. L. Richardson, "Oxidation kinetics and effect of $\mathrm{pH}$ on the degradation of MTBE with Fenton reagent," Water Research, vol. 39, no. 1, pp. 107-118, 2005.

[50] A. A. Burbano, D. D. Dionysiou, and M. T. Suidan, "Effect of oxidant-to-substrate ratios on the degradation of MTBE with Fenton reagent," Water Research, vol. 42, no. 12, pp. 3225-3239, 2008.

[51] M. Vilve, A. Hirvonen, and M. Sillanpää, "Effects of reaction conditions on nuclear laundry water treatment in Fenton process," Journal of Hazardous Materials, vol. 164, no. 2-3, pp. 1468-1473, 2009.

[52] D. Prato-Garcia, R. Vasquez-Medrano, and M. HernandezEsparza, "Solar photoassisted advanced oxidation of synthetic phenolic wastewaters using ferrioxalate complexes," Solar Energy, vol. 83, no. 3, pp. 306-315, 2009.

[53] A. Moncayo-Lasso, C. Pulgarin, and N. Benítez, "Degradation of DBPs' precursors in river water before and after slow sand filtration by photo-Fenton process at $\mathrm{pH} 5$ in a solar CPC reactor," Water Research, vol. 42, no. 15, pp. 4125-4132, 2008.

[54] A. G. Trovó, R. F. P. Nogueira, A. Agüera, A. R. Fernandez-Alba, C. Sirtori, and S. Malato, "Degradation of sulfamethoxazole in water by solar photo-Fenton. Chemical and toxicological evaluation," Water Research, vol. 43, no. 16, pp. 3922-3931, 2009.

[55] J. García-Montaño, F. Torrades, J. A. García-Hortal, X. Domènech, and J. Peral, "Degradation of Procion Red HE7B reactive dye by coupling a photo-Fenton system with a sequencing batch reactor," Journal of Hazardous Materials, vol. 134, no. 1-3, pp. 220-229, 2006.

[56] J.-H. Sun, S.-P. Sun, M.-H. Fan, H.-Q. Guo, Y.-F. Lee, and R.$\mathrm{X}$. Sun, "Oxidative decomposition of p-nitroaniline in water by solar photo-Fenton advanced oxidation process," Journal of Hazardous Materials, vol. 153, no. 1-2, pp. 187-193, 2008.

[57] L.-A. Lu, Y.-S. Ma, M. Kumar, and J.-G. Lin, "Photo-Fenton pretreatment of carbofuran-analyses via experimental design, 
detoxification and biodegradability enhancement," Separation \& Purification Technology, vol. 81, pp. 325-331, 2011.

[58] A. Özcan, M. A. Oturan, N. Oturan, and Y. Şahin, "Removal of Acid Orange 7 from water by electrochemically generated Fenton's reagent," Journal of Hazardous Materials, vol. 163, no. 2-3, pp. 1213-1220, 2009.

[59] B. K. Körbahti and M. A. Rauf, "Determination of optimum operating conditions of carmine decoloration by $\mathrm{UV} / \mathrm{H}_{2} \mathrm{O}_{2}$ using response surface methodology," Journal of Hazardous Materials, vol. 161, no. 1, pp. 281-286, 2009.

[60] T. Essam, M. A. Amin, O. El Tayeb, B. Mattiasson, and B. Guieysse, "Sequential photochemical-biological degradation of chlorophenols," Chemosphere, vol. 66, no. 11, pp. 2201-2209, 2007.

[61] J. Dwyer, L. Kavanagh, and P. Lant, "The degradation of dissolved organic nitrogen associated with melanoidin using a UV/ $\mathrm{H}_{2} \mathrm{O}_{2}$ AOP," Chemosphere, vol. 71, no. 9, pp. 1745-1753, 2008.

[62] M. Sánchez-Polo, J. Rivera-Utrilla, J. D. Méndez-Díaz, S. Canonica, and U. von Gunten, "Photooxidation of naphthalenesulfonic acids: comparison between processes based on $\mathrm{O}_{3}$, $\mathrm{O}_{3}$ /activated carbon and $\mathrm{UV} / \mathrm{H}_{2} \mathrm{O}_{2}$," Chemosphere, vol. 68, no. 10, pp. 1814-1820, 2007.

[63] F. Hernández and G. Geissler, "Photooxidative treatment of sulfurous water for its potabilization," Photochemistry \& Photobiology, vol. 81, no. 3, pp. 636-640, 2005.

[64] C. S. Zalazar, M. L. Satuf, O. M. Alfano, and A. E. Cassano, "Comparison of $\mathrm{H}_{2} \mathrm{O}_{2} / \mathrm{UV}$ and heterogeneous photocatalytic processes for the degradation of dichloroacetic acid in water," Environmental Science \& Technology, vol. 42, no. 16, pp. 61986204, 2008.

[65] J. Mitrović, M. Radović, D. Bojić, T. Anbelković, M. Purenović, and A. Bojić, "Decolorization of the textile azo dye reactive orange 16 by the $\mathrm{UV} / \mathrm{H}_{2} \mathrm{O}_{2}$ process," Journal of the Serbian Chemical Society, vol. 77, no. 4, pp. 465-481, 2012.

[66] Y. J. Jung, W. G. Kim, Y. Yoon, T.-M. Hwang, and J.-W. Kang, "pH effect on ozonation of ampicillin: kinetic study and toxicity assessment," Ozone: Science \& Engineering, vol. 34, no. 3, pp. 156-162, 2012.

[67] Z. S. Can and M. Gurol, "Formaldehyde formation during ozonation of drinking water," Ozone: Science \& Engineering, vol. 25, no. 1, pp. 41-51, 2003.

[68] Y. Qiu, C.-H. Kuo, and M. E. Zappi, "Ozonation kinetics of six dichlorophenol isomers," Ozone: Science \& Engineering, vol. 24, no. 2, pp. 123-131, 2002.

[69] G. Moussavi and M. Mahmoudi, "Degradation and biodegradability improvement of the reactive red 198 azo dye using catalytic ozonation with $\mathrm{MgO}$ nanocrystals," Chemical Engineering Journal, vol. 152, no. 1, pp. 1-7, 2009.

[70] A. Begum and S. K. Gautam, "Endosulfan and lindane degradation using ozonation," Environmental Technology, vol. 33, no. 8, pp. 943-949, 2012.

[71] Y. Ku, H. S. Lin, W. Wang, and C. M. Ma, "Decomposition of phorate in aqueous solution by ozonation," Journal of Environmental Science \& Health Part B, vol. 42, no. 2, pp. 143-149, 2007.

[72] P. K. A. Hong and Y. Zeng, "Degradation of pentachlorophenol by ozonation and biodegradability of intermediates," Water Research, vol. 36, no. 17, pp. 4243-4254, 2002.

[73] H. Hoigne and H. Bader, "Rate constants of reactions of ozone with organic and inorganic compounds in water. II. Dissociating organic compounds," Water Research, vol. 17, no. 2, pp. 185-194, 1983.
[74] K. Y. Li, C. H. Kuo, and J. L. Weeks Jr., "A kinetic study of ozonephenol reaction in aqueous solutions," AIChE Journal, vol. 25, no. 4, pp. 583-591, 1979.

[75] T. Otake, S. Tone, K. Kono, and K. Nakao, "Photo-oxidation of phenols with ozone," Journal of Chemical Engineering of Japan, vol. 12, no. 4, pp. 289-293, 1979.

[76] M. S. Yazgan, C. Kinaci, and I. Toroz, "Ozonation of aqueous solution of alpha endosulfan," Journal of Environmental Science \& Health Part B, vol. 38, no. 6, pp. 843-853, 2003.

[77] J. A. Roth and D. E. Sullivan, "Solubility of ozone in water," Industrial \& Engineering Chemistry Fundamentals, vol. 20, no. 2, pp. 137-140, 1981.

[78] J. L. Sotelo, F. J. Beltrán, F. J. Benítez, and J. Beltrán-Heredia, "Ozone decomposition in water: kinetic study," Industrial \& Engineering Chemistry Research, vol. 26, no. 1, pp. 39-43, 1987.

[79] J. Wu, M. A. Eiteman, and S. E. Law, "Evaluation of membrane filtration and ozonation processes for treatment of reactive-dye wastewater," Journal of Environmental Engineering, vol. 124, no. 3, pp. 272-277, 1998.

[80] J. J. Wu, M. Muruganandham, and S. H. Chen, "Degradation of DMSO by ozone-based advanced oxidation processes," Journal of Hazardous Materials, vol. 149, no. 1, pp. 218-225, 2007.

[81] J.-M. Fanchiang and D.-H. Tseng, "Decolorization and transformation of anthraquinone dye Reactive Blue 19 by ozonation," Environmental Technology, vol. 30, no. 2, pp. 161-172, 2009.

[82] J. J. Wu, M. Muruganandham, L. T. Chang, and S. H. Chen, "Oxidation of propylene glycol methyl ether acetate using ozone-based advanced oxidation processes," Ozone: Science \& Engineering, vol. 30, no. 5, pp. 332-338, 2008.

[83] F. J. Beltrán, J. F. García-Araya, and I. Giráldez, "Gallic acid water ozonation using activated carbon," Applied Catalysis B, vol. 63, no. 3-4, pp. 249-259, 2006.

[84] E. Reisz, W. Schmidt, H.-P. Schuchmann, and C. Von Sonntag, "Photolysis of ozone in aqueous solutions in the presence of tertiary butanol," Environmental Science \& Technology, vol. 37, no. 9, pp. 1941-1948, 2003.

[85] B. Xu, Z. Chen, F. Qi, J. Ma, and F. Wu, "Comparison of Nnitrosodiethylamine degradation in water by UV irradiation and $\mathrm{UV} / \mathrm{O}_{3}$ : efficiency, product and mechanism," Journal of Hazardous Materials, vol. 179, no. 1-3, pp. 976-982, 2010.

[86] Y.-S. Shen and Y. Ku, "Decomposition of gas-phase chloroethenes by $\mathrm{UV} / \mathrm{O}_{3}$ process," Water Research, vol. 32, no. 9, pp. 2669-2679, 1998.

[87] M.-S. Chou and K.-L. Chang, "Oxidation of aqueous dimethyl sulfoxide (DMSO) using $\mathrm{UV}, \mathrm{O}_{3}$, and $\mathrm{UV} / \mathrm{O}_{3}$," Ozone: Science \& Engineering, vol. 29, no. 5, pp. 391-397, 2007.

[88] M. Trapido, A. Hirvonen, Y. Veressinina, J. Hentunen, and R. Munter, "Ozonation, ozone/UV and $\mathrm{UV} / \mathrm{H}_{2} \mathrm{O}_{2}$ degradation of chlorophenols," Ozone: Science \& Engineering, vol. 19, no. 1, pp. 75-96, 1997.

[89] M. S. Lucas, J. A. Peres, and G. Li Puma, "Treatment of winery wastewater by ozone-based advanced oxidation processes $\left(\mathrm{O}_{3}\right.$, $\mathrm{O}_{3} / \mathrm{UV}$ and $\mathrm{O}_{3} / \mathrm{UV} / \mathrm{H}_{2} \mathrm{O}_{2}$ ) in a pilot-scale bubble column reactor and process economics," Separation \& Purification Technology, vol. 72, no. 3, pp. 235-241, 2010.

[90] H. Qi, D.-Z. Sun, and G.-Q. Chi, "Formaldehyde degradation by $\mathrm{UV} / \mathrm{TiO}_{2} / \mathrm{O}_{3}$ process using continuous flow mode," Journal of Environmental Sciences, vol. 19, no. 9, pp. 1136-1140, 2007.

[91] S.-J. Kim, S.-C. Kim, S.-G. Seo et al., "Photocatalyzed destruction of organic dyes using microwave/ $\mathrm{UV} / \mathrm{O}_{3} / \mathrm{H}_{2} \mathrm{O}_{2} / \mathrm{TiO}_{2}$ oxidation system," Catalysis Today, vol. 164, no. 1, pp. 384-390, 2011. 
[92] S. Cortes, J. Sarasa, P. Ormad, R. Gracia, and J. L. Ovelleiro, "Comparative efficiency of the systems $\mathrm{O}_{3} /$ high $\mathrm{pH}$ and $\mathrm{O}_{3} /$ catalyst for the oxidation of chlorobenzenes in water," Ozone: Science \& Engineering, vol. 22, no. 4, pp. 415-426, 2000.

[93] A. A. Abd El-Raady and T. Nakajima, "Decomposition of carboxylic acids in water by $\mathrm{O}_{3}, \mathrm{O}_{3} / \mathrm{H}_{2} \mathrm{O}_{2}$, and $\mathrm{O}_{3}$ /catalyst," Ozone: Science \& Engineering, vol. 27, no. 1, pp. 11-18, 2005.

[94] F. J. Beltrán, F. J. Rivas, and R. Montero-de-Espinosa, “Ozoneenhanced oxidation of oxalic acid in water with cobalt catalysts. 1. Homogeneous catalytic ozonation," Industrial \& Engineering Chemistry Research, vol. 42, no. 14, pp. 3210-3217, 2003.

[95] T. Zhang and J. Ma, "Catalytic ozonation of trace nitrobenzene in water with synthetic goethite," Journal of Molecular Catalysis A, vol. 279, no. 1, pp. 82-89, 2008.

[96] B. Kasprzyk-Hordern, M. Ziółek, and J. Nawrocki, "Catalytic ozonation and methods of enhancing molecular ozone reactions in water treatment," Applied Catalysis B, vol. 46, no. 4, pp. 639-669, 2003.

[97] T. Oyama, T. Otsu, Y. Hidano, T. Koike, N. Serpone, and H. Hidaka, "Enhanced remediation of simulated wastewaters contaminated with 2-chlorophenol and other aquatic pollutants by $\mathrm{TiO}_{2}$-photoassisted ozonation in a sunlight-driven pilotplant scale photoreactor," Solar Energy, vol. 85, no. 5, pp. 938944, 2011.

[98] E. M. Rodríguez, G. Fernández, P. M. Alvarez, and F. J. Beltrán, " $\mathrm{TiO}_{2}$ and $\mathrm{Fe}$ (III) photocatalytic ozonation processes of a mixture of emergent contaminants of water," Water Research, vol. 46, no. 1, pp. 152-166, 2012.

[99] F. J. Beltrán, F. J. Rivas, and O. Gimeno, "Comparison between photocatalytic ozonation and other oxidation processes for the removal of phenols from water," Journal of Chemical Technology and Biotechnology, vol. 80, no. 9, pp. 973-984, 2005.

[100] S. Song, M. Xia, Z. He, H. Ying, B. Lü, and J. Chen, "Degradation of p-nitrotoluene in aqueous solution by ozonation combined with sonolysis," Journal of Hazardous Materials, vol. 144, no. 12, pp. 532-537, 2007.

[101] G. Xu, S. Chen, J. Shi, S. Wang, and G. Zhu, "Combination treatment of ultrasound and ozone for improving solubilization and anaerobic biodegradability of waste activated sludge," Journal of Hazardous Materials, vol. 180, no. 1-3, pp. 340-346, 2010.

[102] J. Herney-Ramirez, M. A. Vicente, and L. M. Madeira, "Heterogeneous photo-Fenton oxidation with pillared clay-based catalysts for wastewater treatment: a review," Applied Catalysis $B$, vol. 98, no. 1-2, pp. 10-26, 2010.

[103] H. Gallard and J. De Laat, "Kinetic modelling of $\mathrm{Fe}(\mathrm{III}) / \mathrm{H}_{2} \mathrm{O}_{2}$ oxidation reactions in dilute aqueous solution using atrazine as a model organic compound," Water Research, vol. 34, no. 12, pp. 3107-3116, 2000.

[104] M. Pera-Titus, V. García-Molina, M. A. Baños, J. Giménez, and S. Esplugas, "Degradation of chlorophenols by means of advanced oxidation processes: a general review," Applied Catalysis B, vol. 47, no. 4, pp. 219-256, 2004.

[105] Y. Deng and J. D. Englehardt, "Treatment of landfill leachate by the Fenton process," Water Research, vol. 40, no. 20, pp. 36833694, 2006.

[106] Y. W. Kang and K.-Y. Hwang, "Effects of reaction conditions on the oxidation efficiency in the Fenton process," Water Research, vol. 34, no. 10, pp. 2786-2790, 2000.

[107] Q. Zhou, W. Li, and T. Hua, "Removal of organic matter from landfill leachate by advanced oxidation processes: a review," International Journal of Chemical Engineering, Article ID 270532, 2010

[108] W. Z. Tang, Physicochemical Treatment of Hazardous Wastes, Lewis, Boca Raton, Fla, USA, 2003.

[109] E. Neyens and J. Baeyens, "A review of classic Fenton's peroxidation as an advanced oxidation technique," Journal of Hazardous Materials, vol. 98, no. 1-3, pp. 33-50, 2003.

[110] P. Wang, I. W. C. Lau, H. H. P. Fang, and D. Zhou, "Landfill leachate treatment with combined UASB and Fenton coagulation," Journal of Environmental Science and Health Part A, vol. 35, no. 10, pp. 1981-1988, 2000.

[111] I. W. C. Lau, P. Wang, and H. H. P. Fang, "Organic removal of anaerobically treated leachate by Fenton Coagulation," Journal of Environmental Engineering, vol. 127, no. 7, pp. 666-669, 2001.

[112] J. Beltran De Heredia, J. Torregrosa, J. R. Dominguez, and J. A. Peres, "Kinetic model for phenolic compound oxidation by Fenton's reagent," Chemosphere, vol. 45, no. 1, pp. 85-90, 2001.

[113] N. Kang, D. S. Lee, and J. Yoon, "Kinetic modeling of Fenton oxidation of phenol and monochlorophenols," Chemosphere, vol. 47, no. 9, pp. 915-924, 2002.

[114] J. A. Zazo, J. A. Casas, A. F. Mohedano, M. A. Gilarranz, and J. J. Rodríguez, "Chemical pathway and kinetics of phenol oxidation by Fenton's reagent," Environmental Science \& Technology, vol. 39, no. 23, pp. 9295-9302, 2005.

[115] S. Basu and I. W. Wei, "Mechanism and kinetics of oxidation of 2,4,6-trichlorophenol by Fenton's reagent," Environmental Engineering Science, vol. 17, no. 5, pp. 279-290, 2000.

[116] P. Bautista, A. F. Mohedano, J. A. Casas, J. A. Zazo, and J. J. Rodriguez, "An overview of the application of Fenton oxidation to industrial wastewaters treatment," Journal of Chemical Technology and Biotechnology, vol. 83, no. 10, pp. 1323-1338, 2008.

[117] Z. M. Li, P. J. Shea, and S. D. Comfort, "Fenton oxidation of 2,4,6-trinitrotoluene in contaminated soil slurries," Environmental Engineering Science, vol. 14, no. 1, pp. 55-66, 1997.

[118] M. Yoshida, B.-D. Lee, and M. Hosomi, "Decomposition of aqueous tetrachloroethylene by Fenton oxidation treatment," Water Science \& Technology, vol. 42, no. 1-2, pp. 203-208, 2000.

[119] K.-D. Zoh and M. K. Stenstrom, "Fenton oxidation of hexahydro-1,3,5-trinitro-1,3,5-triazine (RDX) and octahydro1,3,5,7-tetranitro-1,3,5,7-tetrazocine (HMX)," Water Research, vol. 36, no. 5, pp. 1331-1341, 2002.

[120] J. A. Zazo, J. A. Casas, A. F. Mohedano, and J. J. Rodríguez, "Catalytic wet peroxide oxidation of phenol with a Fe/active carbon catalyst," Applied Catalysis B, vol. 65, no. 3-4, pp. 261268, 2006.

[121] C. B. Molina, J. A. Casas, J. A. Zazo, and J. J. Rodríguez, "A comparison of Al-Fe and $\mathrm{Zr}$-Fe pillared clays for catalytic wet peroxide oxidation," Chemical Engineering Journal, vol. 118, no. 1-2, pp. 29-35, 2006.

[122] S. Kanmani and S. Muthuselvi, "Soil remediation by Fenton/photo Fenton oxidation processes," Journal of the Institute of Public Health Engineers, vol. 2, pp. 5-9, 2005.

[123] P. R. Gogate and A. B. Pandit, "A review of imperative technologies for wastewater treatment I: oxidation technologies at ambient conditions," Advances in Environmental Research, vol. 8, no. 3-4, pp. 501-551, 2004.

[124] F. K. Nesheiwat and A. G. Swanson, "Clean contaminated sites using Fenton's reagent," Chemical Engineering Progress, vol. 96, no. 4, pp. 61-66, 2000.

[125] F. J. Benitez, J. L. Acero, F. J. Real, F. J. Rubio, and A. I. Leal, “The role of hydroxyl radicals for the decomposition of p-hydroxy 
phenylacetic acid in aqueous solutions," Water Research, vol. 35, no. 5, pp. 1338-1343, 2001.

[126] G. Lofrano, S. Meriç, V. Belgiorno, and R. M. A. Napoli, "Fenton's oxidation of various-based tanning materials," Desalination, vol. 211, no. 1-3, pp. 10-21, 2007.

[127] M. I. Badawy, M. Y. Ghaly, and T. A. Gad-Allah, "Advanced oxidation processes for the removal of organophosphorus pesticides from wastewater," Desalination, vol. 194, no. 1-3, pp. 166-175, 2006.

[128] L. Szpyrkowicz, C. Juzzolino, and S. N. Kaul, "A comparative study on oxidation of disperse dyes by electrochemical process, ozone, hypochlorite and Fenton reagent," Water Research, vol. 35, no. 9, pp. 2129-2136, 2001.

[129] F. J. Rivas, F. J. Beltran, J. Frades, and P. Buxeda, "Oxidation of phydroxybenzoic acid by Fenton's reagent," Water Research, vol. 35, no. 2, pp. 387-396, 2001.

[130] C. W. Jones, "Activation of hydrogen peroxide using inorganic and organic species," in Applications of Hydrogen Peroxide and Derivatives, J. H. Clark, Ed., chapter 2, pp. 37-78, Royal Society of Chemistry, Cambridge, UK, 1999.

[131] R. Andreozzi, V. Caprio, A. Insola, and R. Marotta, "Advanced oxidation processes (AOP) for water purification and recovery," Catalysis Today, vol. 53, no. 1, pp. 51-59, 1999.

[132] E. G. Garrido-Ramírez, B. K. G. Theng, and M. L. Mora, "Clays and oxide minerals as catalysts and nanocatalysts in Fenton-like reactions-a review," Applied Clay Science, vol. 47, no. 3-4, pp. 182-192, 2010.

[133] S. Malato, J. Blanco, A. Vidal, and C. Richter, "Photocatalysis with solar energy at a pilot-plant scale: an overview," Applied Catalysis B, vol. 37, no. 1, pp. 1-15, 2002.

[134] J. Kiwi, C. Pulgarin, P. Peringer, and M. Grätzel, "Beneficial effects of homogeneous photo-Fenton pretreatment upon the biodegradation of anthraquinone sulfonate in wastewater treatment," Applied Catalysis B, vol. 3, no. 1, pp. 85-99, 1993.

[135] R. Sauleda and E. Brillas, "Mineralization of aniline and 4chlorophenol in acidic solution by ozonation catalyzed with $\mathrm{Fe}^{2+}$ and UVA light," Applied Catalysis B, vol. 29, no. 2, pp. 135$145,2001$.

[136] M. Tokumura, H. T. Znad, and Y. Kawase, "Decolorization of dark brown colored coffee effluent by solar photo-Fenton reaction: effect of solar light dose on decolorization kinetics," Water Research, vol. 42, no. 18, pp. 4665-4673, 2008.

[137] R. Aplin, A. J. Feitz, and T. D. Waite, "Effect of Fe(III)ligand properties on effectiveness of modified photo-Fenton processes," Water Science \& Technology, vol. 44, no. 5, pp. 2330, 2001.

[138] I. Muñoz, J. Rieradevall, F. Torrades, J. Peral, and X. Domènech, "Environmental assessment of different solar driven advanced oxidation processes," Solar Energy, vol. 79, no. 4, pp. 369-375, 2005.

[139] M. Rodríguez, S. Malato, C. Pulgarin et al., "Optimizing the solar photo-Fenton process in the treatment of contaminated water. Determination of intrinsic kinetic constants for scale-up," Solar Energy, vol. 79, no. 4, pp. 360-368, 2005.

[140] P. R. Gogate and A. B. Pandit, "A review of imperative technologies for wastewater treatment II: hybrid methods," Advances in Environmental Research, vol. 8, no. 3-4, pp. 553-597, 2004.

[141] G. C. Heng, E. S. Elmolla, and M. Chaudhuri, "Optimization of photo-Fenton treatment of mature landfill leachate," Nature Environment and Pollution Technology, vol. 11, no. 1, pp. 65-72, 2012.
[142] W. H. Glaze, J. W. Kang, and D. H. Chapin, "The chemistry of water treatment processes involving ozone, hydrogen peroxide and ultraviolet radiation," Ozone: Science \& Engineering, vol. 9, pp. 335-352, 1987.

[143] M. E. T. Sillanpää, T. A. Kurniawan, and W.-H. Lo, "Degradation of chelating agents in aqueoussolution using advanced oxidation process (AOP)," Chemosphere, vol. 83, no. 11, pp. 1443-1460, 2011.

[144] W. Z. Tang, Physico-Chemical Treatment of Hazardous Wastes, CRC Press, London, UK, 2004.

[145] K. B. Ko, J. Y. Lee, Y. H. Yoon et al., "Effects of nitrate on the UV photolysis of $\mathrm{H}_{2} \mathrm{O}_{2}$ for 2,4-dichlorophenol degradation in treated effluents," Desalination and Water Treatment, vol. 2, no. 1-3, pp. 6-11, 2009.

[146] P. Lei, C. Chen, J. Yang, W. Ma, J. Zhao, and L. Zang, "Degradation of dye pollutants by immobilized polyoxometalate with $\mathrm{H}_{2} \mathrm{O}_{2}$ under visible-light irradiation," Environmental Science \& Technology, vol. 39, no. 21, pp. 8466-8474, 2005.

[147] D. Jiang, S. Zhang, and H. Zhao, "Photocatalytic degradation characteristics of different organic compounds at $\mathrm{TiO}_{2}$ nanoporous film electrodes with mixed anatase/rutile phases," Environmental Science \& Technology, vol. 41, no. 1, pp. 303-308, 2007.

[148] M. A. Brown and J. E. Casida, "Daminozide: oxidation by photochemically generated singlet oxygen to dimethylnitrosamine and succinic anhydride," Journal of Agricultural and Food Chemistry, vol. 36, no. 5, pp. 1064-1066, 1988.

[149] R. Bauer, G. Waldner, H. Fallmann et al., "The photo-Fenton reaction and the $\mathrm{TiO}_{2} / \mathrm{UV}$ process for wastewater treatmentnovel developments," Catalysis Today, vol. 53, no. 1, pp. 131-144, 1999.

[150] F. J. Benitez, J. Beltran-Heredia, J. L. Acero, and F. J. Rubio, "Oxidation of several chlorophenolic derivatives by UV irradiation and hydroxyl radicals," Journal of Chemical Technology and Biotechnology, vol. 76, no. 3, pp. 312-320, 2001.

[151] J. Yoon, S. Kim, D. S. Lee, and J. Huh, "Characteristics of pchlorophenol degradation by photo Fenton oxidation," Water Science \& Technology, vol. 42, no. 3-4, pp. 219-224, 2000.

[152] S. Sabhi and J. Kiwi, "Degradation of 2,4-dichlorophenol by immobilized iron catalysts," Water Research, vol. 35, no. 8, pp. 1994-2002, 2001. 

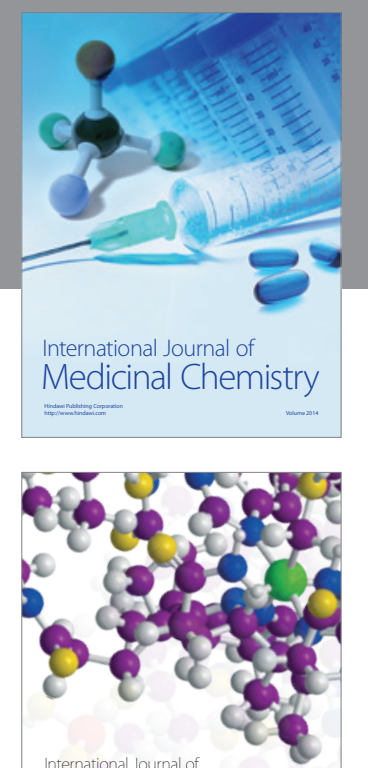

\section{Carbohydrate} Chemistry

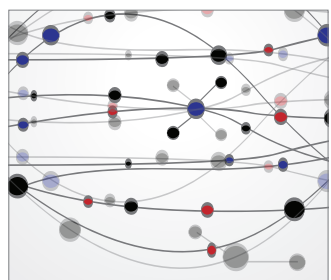

The Scientific World Journal
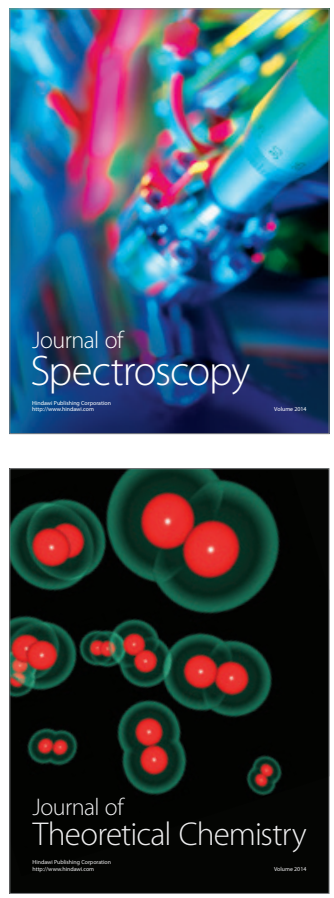
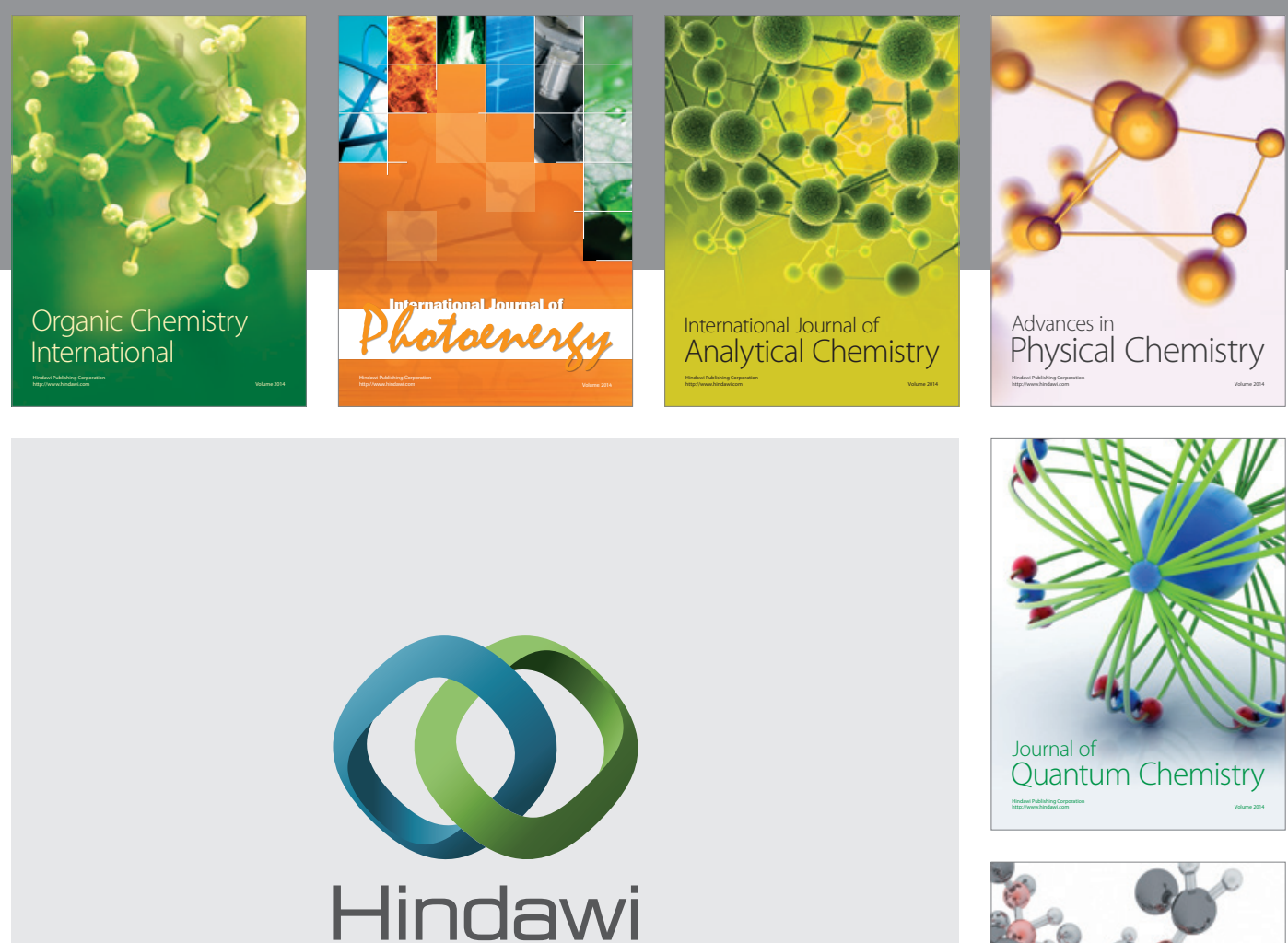

Submit your manuscripts at

http://www.hindawi.com

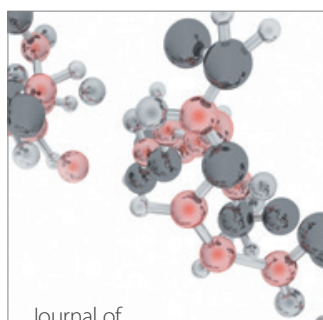

Analytical Methods

in Chemistry

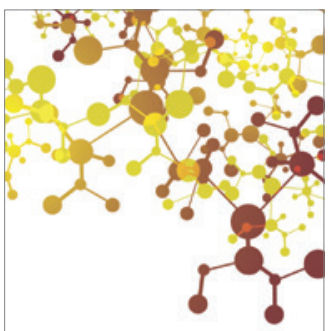

Journal of

Applied Chemistry

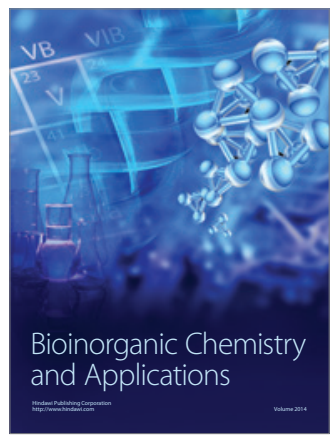

Inorganic Chemistry
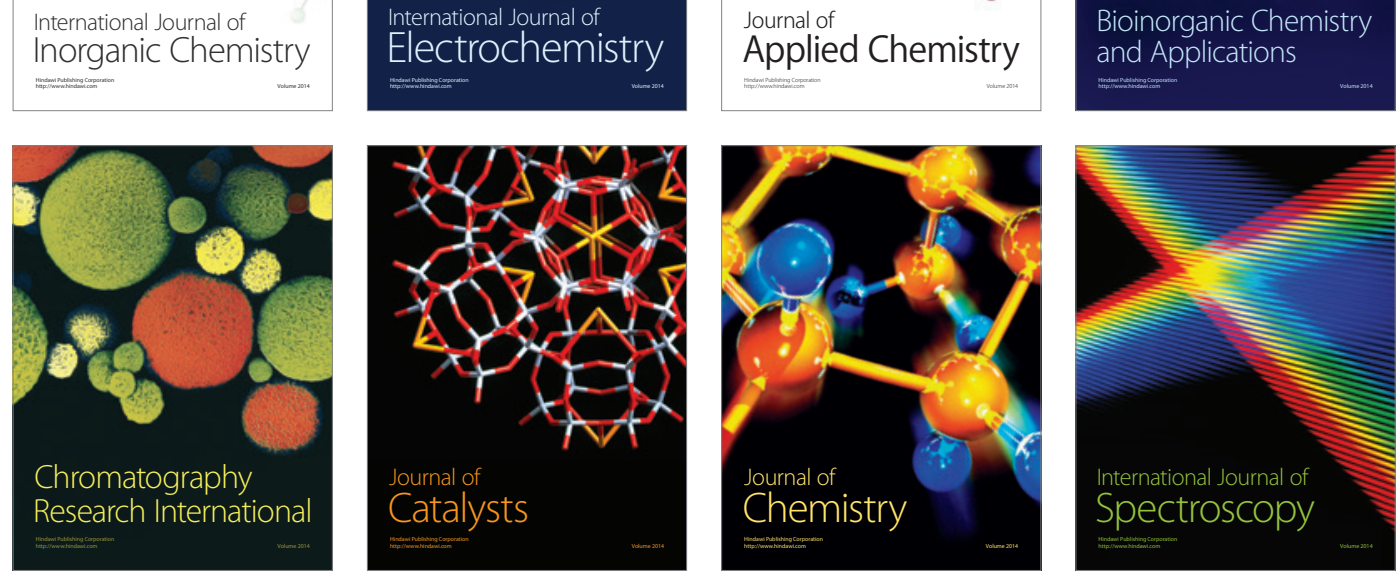